\title{
ON THE EFFECTS OF FUEL PROPERTIES AND INJECTION TIMING ON PARTIALLY PREMIXED COMPRESSION IGNITION OF LOW OCTANE FUELS
}

\author{
NIMAL NASER * MOHAMMED JAASIM, NOUR ATEF, HONG IM \\ SUK HO CHUNG, S. MANI SARATHY* \\ King Abdullah University of Science and Technology (KAUST), \\ Clean Combustion Research Center (CCRC), Thuwal, Saudi Arabia \\ *Corresponding authors: nimal.naser@kaust.edu.sa; mani.sarathy@kaust.edu.sa
}

\section{To cite this article:}

Naser, N., Jaasim, M. Atef, N., Im, H., Chung, S.H. and Sarathy, S.M., "On the effects of fuel properties and injection timing in partially premixed compression ignition of low octane fuels.". Fuel, 207 (2017), pp. 373-388.

\begin{abstract}
A better understanding on the effects of fuel properties and injection timing is required to improve the performance of advanced engines based on low temperature combustion concepts. In this work, an experimental and computational study was conducted to investigate the effects of physical and chemical kinetic properties of low octane fuels and their surrogates in partially premixed compression ignition (PPCI) engines. The main objective was to identify the relative importance of physical versus chemical kinetic properties in predicting practical fuel combustion behavior across a range of injection timings. Two fuel/surrogate pairs were chosen for comparison: light naphtha (LN) versus the primary reference fuel (PRF) with the research octane number of 65 (PRF 65), and FACE (fuels for advanced combustion engines) I gasoline versus PRF 70. Two sets of parametric studies were conducted: the first varying the amount of injected fuel mass at different injection timings to match a fixed combustion phasing, and the second maintaining the same injected fuel mass at each injection timing to assess the resulting combustion phasing changes. Full-cycle computational fluid dynamic engine simulations were conducted by accounting for the differences in the physical properties of the original and surrogate fuels, while employing identical chemical kinetics. The
\end{abstract}


simulations were found to capture the trends observed in the experiment, while providing details on the spatial mixing and chemical reactions for different fuels and injection timings. It was found that the differences in the physical properties become increasingly important for later injection timing conditions, and the observed differences in the behavior were properly explained by the analysis of the mixture stratification patterns resulting from injection of fuels with different physical properties. The results suggest that accurate description of both physical and chemical behavior of the fuels is critical in predictive simulations of PPCI engines for a wide range of injection timings.

Changes in global energy needs and increasingly stringent emissions regulations demand future internal combustion engines to operate on fuels that are notably different from those used today. This has motivated research into new fuels and combustion processes, as well as fuel-engine interactions. The partially premixed compression ignition (PPCI) engine [1, 2] is one new engine combustion concept that warrants such research. PPCI engines are similar in operation to conventional diesel engines [3], but the injection timings are varied more widely to achieve desirable levels of partial mixing or fuel stratification. For such applications, fuels with longer ignition delay times than diesel are ideal to promote mixing before ignition occurs and thereby mitigate emissions generated due to locally rich fuel packets in conventional diesel combustion [4].

Although PPCI engine concepts have attracted considerable interest, the optimum fuel for such an engine remains an open question [5, 6, 7]. Hildingsson et al. [5] reported that an optimum fuel for PPCI engines should lie in the octane number (ON) range of $75-85$. Naphtha is a less processed petroleum fraction in this lower ON range, and has emerged as a promising candidate for PPCI engine applications [8, 9, 10, 11]. In this study, two full-blend low octane fuels, J-24 light naphtha (LN) obtained from Saudi Aramco and the fuels for advanced combustion engines (FACE) I gasoline [12] (which will be collectively referred to as practical fuels), are selected as test fuels to investigate PPCI engine combustion characteristics. Important properties of LN and FACE I are given in Table I. A distinct feature of these low octane fuels is their relatively low octane sensitivity $(S)$, defined as the difference between the research octane number $(\mathrm{RON})$ and motor octane number $(\mathrm{MON})$ [13, 14] ( $=\mathrm{RON}-\mathrm{MON})$. Typical gasoline fuels have $S$ in the range of 7 to 12 [15], while LN and FACE I have S less than 1. Further details will be discussed later.

Practical petroleum fuels contain a large number of components whose physical and chemical properties are difficult to model in chemical kinetic and engine simulations. Therefore, a systematic way to characterize a practical fuel's behavior in engines is to represent it with a surrogate fuel. Primary reference fuels (PRF), mixtures of isooctane and $n$-heptane, are commonly used surrogates to describe gasoline combustion 
Table 1: Fuel properties

\begin{tabular}{lcccc}
\hline Fuel & Light naphtha & PRF 65 & FACE I gasoline & PRF 70 \\
\hline RON & 64.2 & 65.0 & 70.3 & 70.0 \\
Sensitivity & 0.6 & 0.0 & 0.7 & 0.0 \\
Density $\left(\mathrm{kg} / \mathrm{m}^{3}\right.$ ) & 642 & 689 & 688 & 690 \\
H/C & 2.34 & 2.26 & 2.25 & 2.26 \\
Stoichiometric AFR & 15.15 & 15.04 & 14.49 & 15.05 \\
Viscosity (cSt) & & \multicolumn{2}{c}{$<$ 1.0 } & \\
\hline Paraffins (\% mass) & 53.6 & 37.9 & 14.6 & 32.7 \\
iso-Paraffins (\% mass) & 36.7 & 62.1 & 70.5 & 67.3 \\
Aromatics (\% mass) & 1.3 & 0 & 4.6 & 0 \\
Naphthenes (\% mass) & 6.6 & 0 & 4.2 & 0 \\
Olefins (\% mass) & 0 & 0 & 6.0 & 0 \\
\hline
\end{tabular}

behavior. PRF mixtures have zero octane sensitivity by definition, while the presence of cycloalkanes, aromatics, alkenes, and oxygenates introduces octane sensitivity in gasoline [16, 17]. As suggested in a previous work [18], the key targets for a surrogate to match are the practical fuel's chemical kinetic properties indicated by its RON and MON (and thus S). Empirical correlations proposed by Kalghatgi et al. [19, 20] can be used to formulate toluene primary reference fuels (TPRFs) comprising toluene, isooctane, and $n$-heptane to match a target fuel's RON and MON. Note that TPRF mixtures with matching $\mathrm{RON}$ and $\mathrm{MON}$ can reproduce the engine performance characteristics of full boiling range gasolines in spark ignition engines [19] and premixed compression ignition engines [18]. Based on the aforementioned criteria and the fuel properties in Table 1. PRF surrogates for J-24 LN and FACE I fuels in the current study are PRF 65 and PRF 70, respectively. In a recent study, Javed et al. [21] measured and simulated ignition delay times of J-24 LN and PRF 65 in a shock tube (ST) and rapid compression machine (RCM) over a broad range of temperatures $(640-1250 \mathrm{~K})$, pressures (20 and 40 bar) and equivalence ratios $(\phi=0.5,1$ and 2). Their results showed that the homogeneous ignition characteristics of LN (RON 65) and PRF 65 were indistinguishable under the higher temperature ST conditions (above $800 \mathrm{~K}$ ), but differences were observed at the $\mathrm{RCM}$ conditions for temperature in the range of $640-780 \mathrm{~K}$.

The main motivation of the present work is to examine whether PRF mixtures are suitable surrogates for naphtha fuels when utilized under PPCI engine conditions. PPCI operation involves a range of fuel vaporization and mixture stratification conditions that depend on injection timing and fuel properties; thus, our hypothesis is that physical processes, in addition to chemical kinetics, may play an important role in reproducing combustion behavior of naphtha fuels. The relative importance of physical processes versus chemical kinetics depends on whether the nature of combustion in the PPCI engine is controlled by evaporation/mixing or homogeneous ignition chemistry. Since PPCI operation involves a wide range of start of injection (SOI) timings, it is anticipated that the relative importance between the physical and chemical kinetic properties of the 
surrogate fuels varies as the SOI changes from nearly homogeneous charge compression ignition (HCCI) with early fuel injection to diesel-like conditions with late injection. In a previous work [22], it was shown that PRFs are suitable surrogates for various low octane fuels under naturally aspirated HCCI conditions, which suggests that matching chemical kinetic ignition properties is sufficient under such homogeneous conditions. The present study aims to advance our understanding through engine experiments accompanied by full-cycle computational fluid dynamic engine simulations using realistic chemical kinetics and physical properties of the fuels under consideration. Detailed analysis of spatial and temporal structures inside the engine provide insights into the relationship between injection timing, fuel physical properties, mixture fraction distribution, and combustion.

Experiments were performed on a single cylinder compression ignition engine (AVL 5402 ) with a compression ratio (CR) of $17: 1$, which is equipped with a common rail fuel injector. This CR for the present HCCI/PPCI tests is similar to that previously used in the literature [23, 24, 25]. The main motivation in conducting HCCI experiments is to demonstrate that HCCI mode is kinetically controlled, which is already well known in engine literature. In such a combustion mode, the effect of physical properties of fuel are minimal, while autoignition chemistry, dictated by the pressure and temperature histories during compression process, plays a vital role [26, 27]. The experimental approach used in the present work is similar to previous work done in [28, 29, 30] which swept the SOI and adjusted the operating conditions to achieve a fixed combustion phasing corresponding to $50 \%$ heat release $\left(\mathrm{CA}_{50}\right)$. Detailed engine specifications are provided in Table 2. A single pulse of fuel was injected at an injection pressure of 300 bar via a Bosch 7 hole diesel injector with a spray included angle of $142^{\circ}$ and orifice diameters of $0.18 \mathrm{~mm}$. The injection pressure of 300 bar was the lowest operating pressure applicable for the specific Bosch diesel injector. Due to strong squish flows and the wider spray angle, a higher injection pressure than GDI-like conditions was required in our experiments to enable greater fuel penetration into the bulk air. An optimal pressure of 300 bar was chosen such that the pressure was as close to GDI possible and sufficient penetration was obtained. Table 3 lists the fuel injection system specifications. To prevent damage to the injection system when PRFs and LN are used, a lubricity additive at concentrations less than 2 ppm was added.

Table 1 showed the properties of the four fuels tested in the study: J-24 LN and its surrogate, PRF 65; FACE I gasoline and its surrogate, PRF 70. These fuels were tested in both HCCI and PPCI modes. Each pair of fuel and corresponding surrogate has similar octane numbers, implying that their gas-phase chemical kinetics and ignition delay times are similar [32, 33, 34]. However, the physical properties for the practical fuels and surrogates are notably different. LN is comprised of lighter hydrocarbons and has 
Table 2: Engine specifications.

\begin{tabular}{lc}
\hline Description & Specification \\
\hline Bore & $85 \mathrm{~mm}$ \\
Stroke & $90 \mathrm{~mm}$ \\
Compression ratio & $17: 1$ \\
Intake pressure & $1.0 \mathrm{bar}$ \\
Intake temperature & $298 \mathrm{~K}$ \\
Engine displacement & $0.51 \mathrm{~L}$ \\
Piston geometry & Re-entrant \\
Bowl depth & $10 \mathrm{~mm}$ \\
Valve type & DOHC \\
Number of valves & 2 intake, 1 exhaust \\
Intake port & 1 helical, 1 tangential \\
Swirl ratio & $1.78^{1}$ \\
Intake valve open (IVO) & 30 CAD $\mathrm{bTDC}^{2}$ \\
Intake valve close (IVC) & 45 CAD aBDC \\
Exhaust valve open (EVO) & 50 CAD bBDC \\
Exhaust valve open (EVC) & 25 CAD aTDC \\
Coolant temperature & $353 \mathrm{~K}$ \\
Lubricant temperature & $353 \mathrm{~K}$ \\
\hline
\end{tabular}

${ }^{1}$ Obtained from [31]

${ }^{2}$ Crank angle degree

Table 3: Fuel injection system specifications.

\begin{tabular}{lc}
\hline Description & Specification \\
\hline Injector type & Common rail diesel piezo-injector \\
Injector model & Bosch $(0445116030)$ \\
Fuel injection pressure & $300 \mathrm{bar}$ \\
Injector holes & 7 \\
Nozzle hole diameter & $0.18 \mathrm{~mm}$ \\
Spray included angle & $142^{\circ}$ \\
\hline
\end{tabular}


a lower density than FACE I and both the PRF 65/70 surrogates, which all have similar density. Furthermore, the distillation characteristics obtained with advanced distillation curve (ADC) method [35] for LN and FACE I are significantly different, as shown in Fig. I, in which temperature versus volume recovered is plotted. A large fraction of LN vaporizes from 310 to $330 \mathrm{~K}$ with a final boiling point near $350 \mathrm{~K}$, while FACE I vaporizes from 350 to $375 \mathrm{~K}$. In comparison, both PRFs vaporize near $373 \mathrm{~K}$, which are close to the boiling range of FACE I, albeit slightly higher. Note that the boiling points (BPs) of $n$-heptane and iso-octane are 371.4 and $372.5 \mathrm{~K}$, respectively.

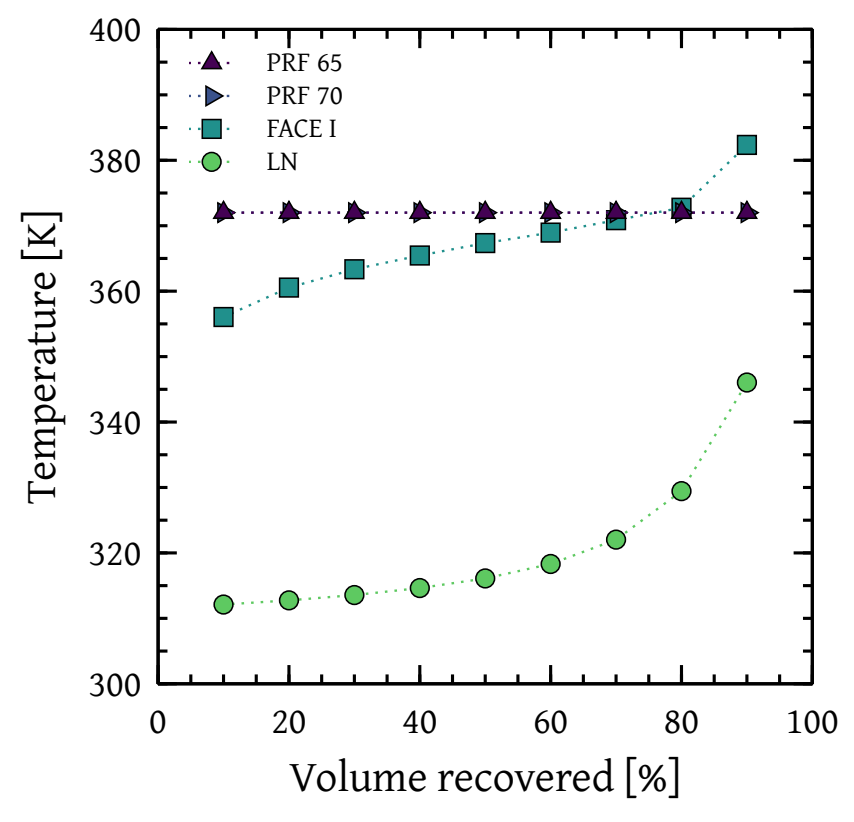

Figure 1: Distillation curves for all the tested fuels.

In the present study, two sets of experimental data are obtained. The first set of experiments, four SOI conditions are tested, and at each SOI, the amount of each fuel was adjusted to achieve a fixed combustion phasing of 4 CAD ATDC, similar to the work performed in [30]. The second set of experiments measured the change in combustion phasing when the amount of each fuel was fixed to that of PRF 65 required to achieve a CA50 of 4 CAD ATDC at each SOI condition. The CA50 used throughout this study is the average of 300 cycles and the maximum uncertainty in CA5O was observed to be $\pm 12 \%$.

Experimental engine conditions for the first set of data are given in Table 4, where $\lambda$ is the reciprocal of $\phi\left(\lambda=\frac{1}{\phi}\right)$ and COV is the coefficient of variation discussed in the succeeding paragraph. The $\lambda$ values given in Table 4 are obtained with a lambda sensor with sensor parameters like $\mathrm{H} / \mathrm{C}$ ratio, stoichiometric air-fuel ratio (AFR), $\mathrm{H}_{2} \mathrm{O}$ content changed according to the fuel used. The maximum rate of pressure rise $\left(R_{\max }\right)$ during HCCI and PPCI combustion are also provided. All experiments were operated at a 
Table 4: Engine experimental test conditions for first set of experiments.

\begin{tabular}{lcccccc}
\hline Fuel & SOI (CAD bTDC) & $\dot{m}_{\text {fuel }}(\mathrm{mg} /$ cycle) & IMEP (bar) & $\lambda$ & $R_{\max }(\mathrm{bar} / \mathrm{deg})$ & COV (\%) \\
\hline LN & & 15.4 & 3.4 & 3.11 & 4.60 & 3.2 \\
PRF 65 & \multirow{2}{*}{300} & 17.4 & 3.5 & 2.77 & 4.80 & 2.4 \\
FACE I & & 18.0 & 3.7 & 2.78 & 5.17 & 1.8 \\
PRF 70 & & 16.6 & 3.7 & 2.90 & 5.40 & 3.2 \\
\hline LN & & 19.3 & 3.4 & 2.48 & 4.07 & 3.6 \\
PRF 65 & \multirow{2}{*}{35} & 15.5 & 2.5 & 3.11 & 2.83 & 4.8 \\
FACE I & & 22.7 & 4.0 & 2.21 & 5.44 & 2.2 \\
PRF 70 & & 22.0 & 3.8 & 2.19 & 5.41 & 2.5 \\
\hline LN & & 14.5 & 3.6 & 3.55 & 6.60 & 1.0 \\
PRF 65 & \multirow{2}{*}{25} & 12.4 & 2.9 & 4.18 & 3.93 & 3.0 \\
FACE I & & 18.2 & 4.0 & 2.95 & 8.25 & 1.5 \\
PRF 70 & & 16.6 & 3.9 & 3.12 & 7.65 & 1.7 \\
\hline LN & & 13.7 & 3.6 & 3.34 & 7.90 & 0.9 \\
PRF 65 & \multirow{2}{*}{19} & 12.2 & 3.0 & 3.78 & 5.62 & 3.6 \\
FACE I & & 17.9 & 4.1 & 2.67 & 10.42 & 1.5 \\
PRF 70 & & 15.8 & 3.9 & 2.92 & 9.27 & 2.5 \\
\hline
\end{tabular}

fixed intake air temperature of $298 \mathrm{~K}$, an intake air pressure of 1 bar. For comparison of different fuels at a specified SOI, the amount of fuel injected was adjusted to match the combustion phasing at 4 CAD ATDC.

For the HCCI tests, the fuel was direct-injected to the engine cylinder during the intake stroke at $300 \mathrm{CAD}$ BTDC, and these conditions were maintained for all the fuels. For the PPCI tests, three injection timings, 35, 25, and 19 CAD BTDC, were selected to evaluate the effects of progressively delayed injection timing on partially premixed combustion. In conducting the first set of experiments under the PPCI conditions, PRF 65 and PRF 70 ignited earlier than LN and FACE I, respectively, so the latter fuels were injected in larger amounts to maintain the combustion phasing at 4 CAD ATDC. It is to be noted that maintaining a constant combustion phasing for the first set of experiments resulted in changes in the indicated mean effective pressure (IMEP). More details on the engine-out emissions are given in Table $\mathrm{S}_{1}$ in Supplementary Material.

Engine experimental test conditions for the second set of experiments with PRF 65 are available in Table 5, details for LN, FACE I and PRF 70 are available in SM, Tables $\mathrm{S}_{2}$, $\mathrm{S}_{3}$, and $\mathrm{S}_{4}$ respectively. As stated previously, the mass of PRF 65 required to achieve a fixed combustion phasing of ${ }_{4}$ CAD ATDC was identified, and all other fuels were injected with this same mass to observe the change in CA50. In the second set of experiments, IMEP is similar across all cases.

For all tests, the mass of air entering the engine cylinder remains fixed, thereby changes in fueling rates causes changes to the global $\phi$ in the engine combustion chamber. Cylinder pressure traces of 300 cycles were obtained with a plug- type pressure transducer (AVL GU22C) mounted in the engine cylinder. Due to cycle-tocycle variation in IC engines, instead of cycle average, a representative pressure trace 
Table 5: Engine experimental test conditions for second set of experiments with PRF 65.

\begin{tabular}{cccccc}
\hline SOI (CAD bTDC) & $\dot{m}_{\text {fuel }}(\mathrm{mg} /$ cycle $)$ & IMEP $(\mathrm{bar})$ & $\lambda$ & $R_{\max }(\mathrm{bar} / \mathrm{deg})$ & COV $(\%)$ \\
\hline 130 & 19.9 & 3.3 & 2.41 & 1.92 & 4.2 \\
100 & 21.5 & 3.2 & 2.14 & 2.04 & 3.5 \\
70 & 21.5 & 3.2 & 2.11 & 2.35 & 2.2 \\
60 & 21.0 & 3.2 & 2.28 & 2.67 & 2.5 \\
50 & 19.4 & 2.8 & 3.36 & 2.21 & 1.9 \\
45 & 17.6 & 2.4 & 2.54 & 1.65 & 3.4 \\
40 & 16.4 & 2.5 & 2.83 & 2.04 & 2.4 \\
35 & 15.3 & 2.5 & 3.01 & 1.90 & 4.1 \\
30 & 13.9 & 2.8 & 3.34 & 2.56 & 3.2 \\
25 & 12.3 & 3.0 & 3.92 & 2.60 & 3.8 \\
20 & 10.9 & 3.1 & 4.26 & 2.41 & 2.8 \\
15 & 12.2 & 3.3 & 3.75 & 6.22 & 3.2 \\
\hline
\end{tabular}

that is statistically most significant by minimizing the sum of squared errors (SSE) 36 based on $\mathrm{CA}_{50}$ is used throughout the paper. Cycle-to- cycle variations indicating combustion stability of engine experimental data is characterized by the coefficient of variation (COV) of IMEP defined as:

$$
C O V_{I M E P}=\frac{\sigma_{I M E P}}{\mu_{I M E P}}
$$

where $\sigma$ and $\mu$ are the standard deviation and the mean of IMEP, respectively. For all experimental data obtained, COV is maintained below $5 \%$.

\section{COMPUTATIONAL METHOdOLOGY}

Full-cycle $3 \mathrm{D}$ simulations were performed using the CONVERGE ${ }^{\mathrm{TM}}$ software [37]. The Reynolds-averaged Navier-Stokes (RANS) with the renormalization group (RNG) $\mathrm{k}$-ffl models were adopted for turbulent flows, and the multi-zone SAGE combustion sub-model [38] was used with the bin sizes of temperature and equivalence ratio of 5 $\mathrm{K}$ and 0.05 , respectively. A reduced PRF chemical kinetic mechanism with 56 species and 168 reactions developed by Liu et al. [39] was used to represent the gas-phase combustion kinetics for all the PRF fuels. This mechanism has been thoroughly validated for PRFs and it showed similar predictive capability as the detailed chemical kinetic PRF mechanism from Lawrence Livermore National Laboratory [40]. PRF 65 and PRF 70 were chosen to represent LN and FACE I, respectively, in terms of chemical kinetic behavior. Javed et al. [21] showed that the ignition delay times of J-24 LN at ranges of temperatures and pressures of interest can be captured accurately with PRF 65 simulations. The reduced PRF chemical kinetic model [39] is validated with measured ignition delay times of LN in shock tubes (ST) and rapid compression machine (RCM) given in [21]. The model was validated at three equivalence ratios, $\phi=0.5,1.0$ and 2.0, as shown in Fig. S1. The model is able to predict ignition delay 
times accurately across the entire range of pressures and temperatures measured in the ST. At lower temperatures corresponding to RCM experiments, the PRF kinetic model under predicts the ignition delay times measured for LN. Javed et al. [21] showed that including more complexity in the surrogate formulation (i.e., including up to 5 components in the surrogate) enabled better predictions of the LN experimental RCM measurements. It should be noted that the predictions by the skeletal PRF kinetic model display similar level of accuracy as obtained with LLNL's detailed PRF chemical kinetic model [40]. Our objective is to qualitatively study the effects of the physical properties of fuels on combustion characteristics, so any conclusions drawn are largely insensitive to uncertainties in the gas-phase chemical kinetics model. Note that the numerical simulations was not intended to reproduce experimental results, but to conduct sound "numerical experiments" using the same boundary conditions as the engine experiments and obtain better understanding of the in-cylinder characteristics by examining the spatial distribution of the mixture composition and reactions, focused mainly on the effect of physical properties of the fuels.

The Kelvin-Helmholtz-Rayleigh-Taylor (KH-RT) break-up model [41] was used for the Lagrangian spray parcels, with built-in standard model parameters set for the experimental spray injection conditions given in Table 3. The Frössling model [42] was used to account for droplet evaporation and the O'Rourke model [43] was used for the droplet dispersion. A square rate of injection profile was used for the simulations, as similar profiles were used during experiments [44].

Following a common practice [45], prior to combustion simulations the engine motoring curve at $1250 \mathrm{rpm}$ was matched by adjusting the compression ratio to 16.5:1 in order to account for the trapped exhaust gases, heat transfer and blow-by of $4.41 / \mathrm{min}$ measured experimentally. The simulated and experimental motoring pressure trace is

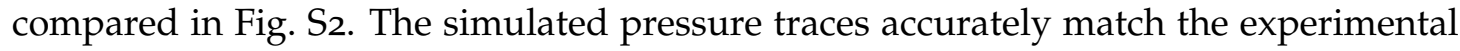
trace. All simulations were carried out from exhaust valve opening (EVO) of the previous cycle to the end of power stroke of the simulated cycle. The wall heat transfer model by O'Rourke [46] was employed. Motoring simulation was carried out with the same experimental conditions, while the boundary temperature was raised by $25 \mathrm{~K}$ for combustion runs to account for temperature rise resulting from combustion [45]. A first-order fully implicit scheme was used for time integration and a second-order finite volume scheme was adopted for the spatial discretization.

Simulations were performed with various base mesh sizes $4 / 2 / 1 \mathrm{~mm}$ (in all directions, Cartesian grid) with different levels of adaptive mesh refinement (AMR). Grid independence was observed with minimum cell size of $0.125 \mathrm{~mm}$, which properly captured the events including swirl motion inside the cylinder during intake. Additional mesh embedding was used to capture the spray physics inside the domain as demonstrated by Kodavasal et al. [45]. As a result, grid with minimum cell size of $0.125 \mathrm{~mm}$ was used for all engine simulations in the present work. Figure 2 shows the 
final grid obtained at ${ }_{4}$ CAD BTDC with SOI at 20 CAD BTDC, together with different levels of AMR shown in inset.

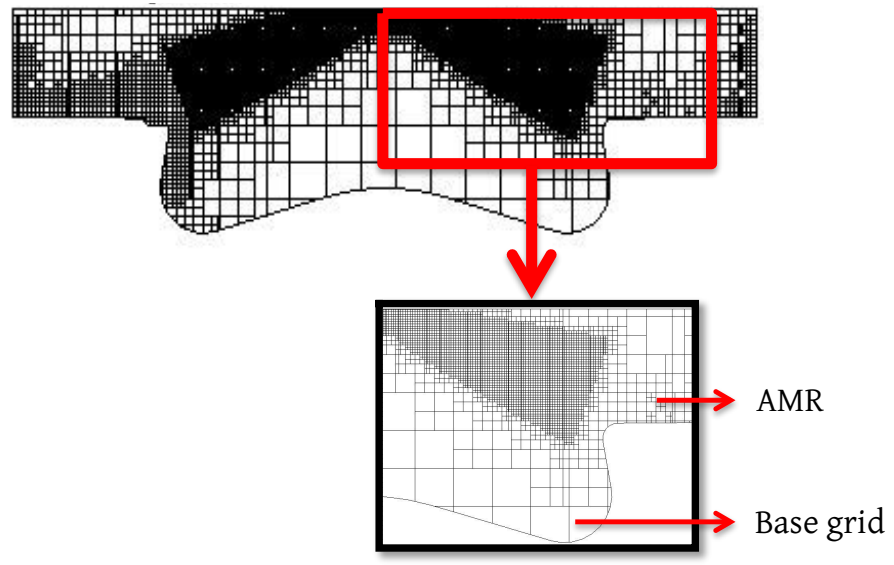

Figure 2: Computational grid of engine cylinder during spray injection event with fixed embedding near the nozzle at 14 CAD BTDC with SOI at 20 CAD BTDC, as shown in the inset.

The spray models used in engine simulations were validated against the engine combustion network's (ECN) target "Spray A" [47] data for vapor penetration length, and satisfactory agreement with experiments was obtained as shown in Fig $\mathrm{S}_{3}$. More detailed information of simulated conditions for "Spray A" case can be found in [47]. The simulations were executed in a consistent manner as the experiments. The intake air temperature, intake air pressure, and injection timings were fixed to those in the experiments. Simulations for the practical fuels of LN and FACE I were performed by changing the liquid properties of those from PRF 65 and PRF 70, respectively, while maintaining the same gas-phase chemical kinetics. Variation of surface tension (computed) of all the fuels with liquid temperature is shown in Fig. 3(a). Despite the presence of physical surrogates for LN and FACE I [48, 49], the study focused on keeping the same components of the PRF surrogates (isooctane and $n$-heptane) to represent chemical kinetics. Accordingly, the surrogates developed by [48, 49] were used to calculate the physical properties of LN and FACE I assuming mass basis additivity. LN has lower surface tension amongst all the fuels, while FACE I, PRF 65, and PRF 70 have comparable surface tensions at all temperatures.

Non-reacting constant volume chamber simulations were performed with a single hole injector similar to the injector used for engine experiments to understand fuel effects in a quiescent chamber in the absence of initial turbulence. The quiescent chamber had cylinder of diameter and height 85 and $90 \mathrm{~mm}$, respectively, which are same dimensions as the bore and stroke of the engine cylinder; more details are available in A. A fuel with lower surface tension leads to smaller droplet Sauter mean diameter (SMD), as shown for the spray simulations in the constant volume chamber 

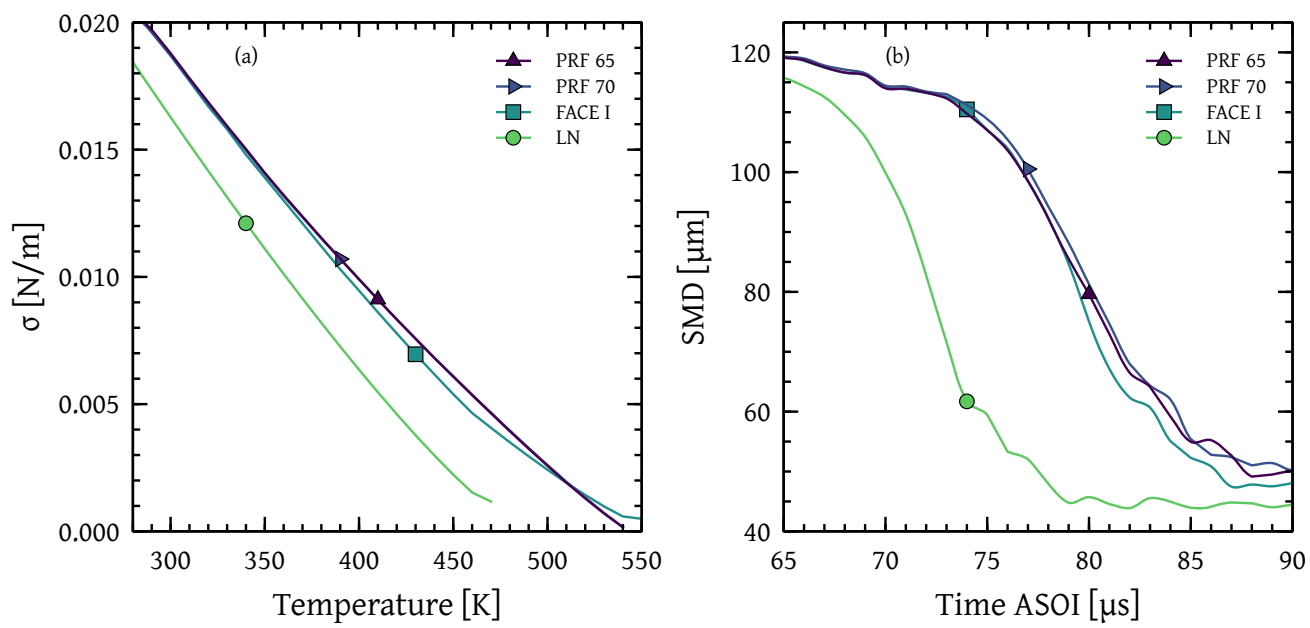

Figure 3: (a) Computed surface tension of tested fuels with temperature and (b) comparison of SMD in a constant volume chamber.

in Fig. 3(b) This can result in more rapid fuel/air mixing, as more fuel vapor can be easily attained. Fig. 3(a) and 3(b) shows that LN can easily enter gas phase due to its higher volatility. Also shown in $B$ are in-cylinder SMD of all fuels at different SOI in engine simulations. These results also show consistent trends as observed in a constant volume combustion chamber, wherein LN has the lowest SMD among all fuels. Thus, the high volatility and lower surface tension of the LN fuel may have significant impacts on combustion characteristics, especially at late injection timings. When the fuel physical properties were changed from those of PRF to those of the practical fuel, the combustion phasing was shifted, as will be discussed later. This effect led to further assessment of the importance of liquid properties on fuel vaporization, local mixture conditions, and combustion phasing that occurs in $\mathrm{HCCI} / \mathrm{PPCI}$ engines.

\section{RESULTS AND DISCUSSION}

The experimental results under the HCCI conditions are presented first along with the numerical results, followed by the PPCI results. Numerical simulation data are used to provide detailed spatial information and rationalize the observed experimental trends. Comparisons are made to highlight the differences between early and late injections, and the real fuels relative to their surrogates. Similar to the second set of experiments, all simulations maintained the injected fuel mass constant for each pair of LN/PRF 65 and FACE I/PRF 70, respectively. This was not only for convenience of the parametric study, but was also intended to provide answers from a complementary parametric variation. 

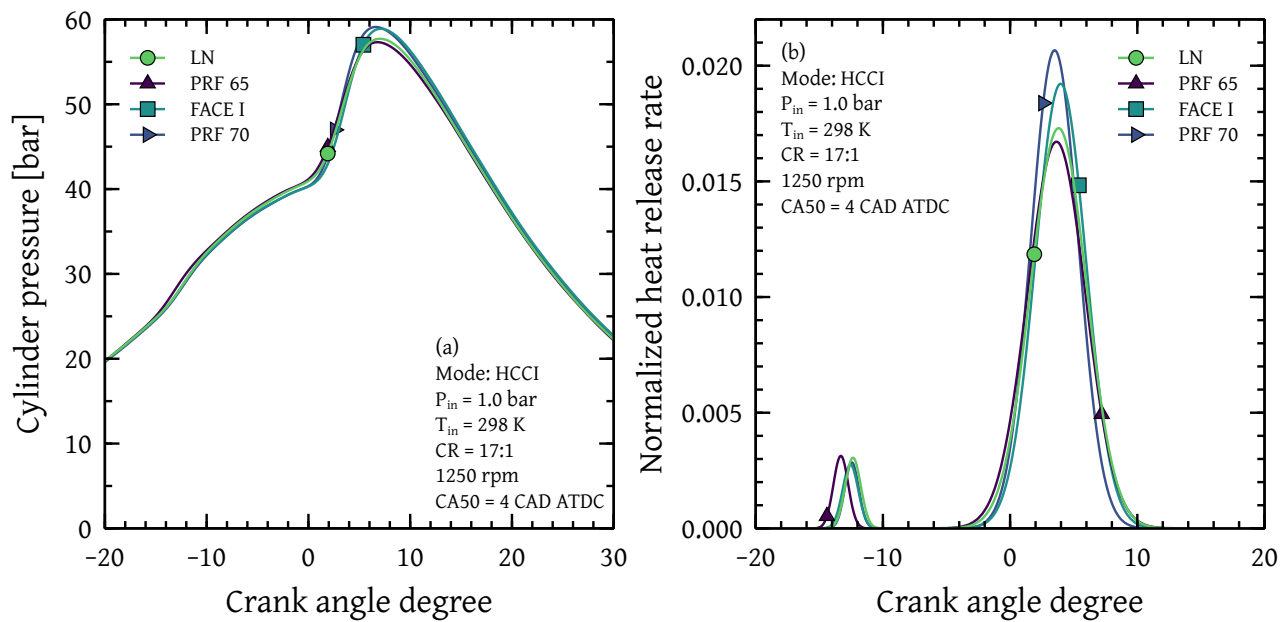

Figure 4: (a) Cylinder pressure traces and (b) normalized heat release rates for tested fuels in HCCI mode.

In the HCCI tests, it is to be noted that the fuel was direct-injected during the intake stroke (300 CAD BTDC) far above the piston bowl, allowing for nearly complete mixing prior to combustion. As such, HCCI combustion is primarily controlled by chemical kinetic processes [26, 27]. Table 4 showed that the amount of each fuel injected for the CA5o to be at 4 CAD ATDC; the difference across all fuels was less than $10 \%$ for a specified injection timing.

Representative pressure traces in the HCCI tests are presented in Fig. 4(a) for all fuels tested. The pressure traces reasonably coincide for all the cases, especially prior to the main heat release upto 4 CAD ATDC, demonstrating that differences in fuel physical and chemical properties do not significantly alter combustion performance under this kinetically controlled regimes. A difference of 5 octane points from PRF 65 to PRF 70 does not have significant effect on HCCI combustion characteristics. Figure 4(b) shows corresponding heat release rates (HRRs) normalized against the total heat release rates for each fuel across the entire cycle. All subsequent results of the heat release rates are normalized in the same way. The overall HRRs among different fuels exhibit a similar level of agreement, including the low temperature heat release (LTHR) observed approximately at 15 CAD BTDC. For the high temperature heat releases, LN and PRF 65 are in good agreement, so as FACE I and PRF 70. The overall results confirm that PRFs indeed capture the combustion characteristics of LN and FACE I fuels, at kinetically controlled HCCI conditions.

In simulations, the difference between the LN and PRF 65 fuels, represented by different physical property data, was investigated under HCCI conditions. Figure 5 shows the comparison of the two fuel cases in the HCCI condition. Both fuels yield nearly identical behavior for the same mass of fuel injected. As anticipated, early 
injection provides enough time for both fuels to be nearly completely mixed before ignition (defined by the rise in $\mathrm{OH}$ mass fraction) regardless of the different physical properties. Autoignition in HCCI is dominated by chemical kinetics and primary reference fuels are good kinetic surrogates, as discussed in [22, 50].

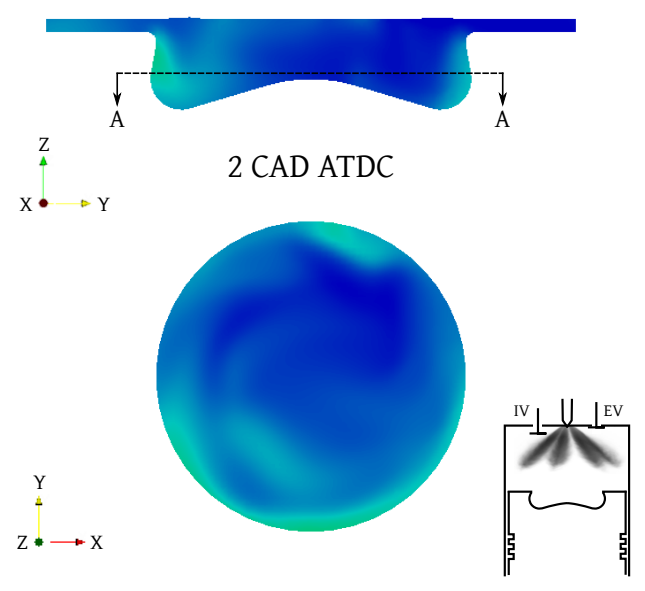

PRF 65

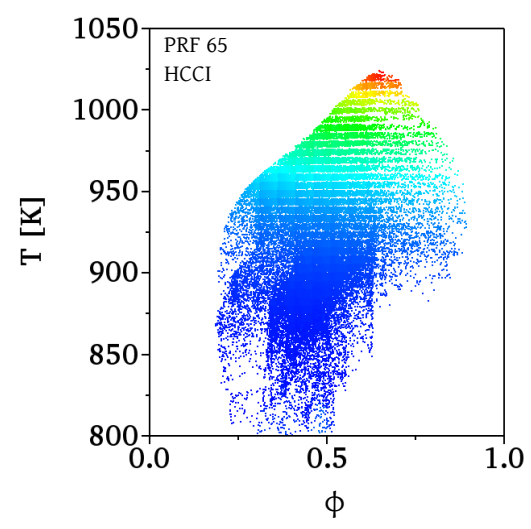

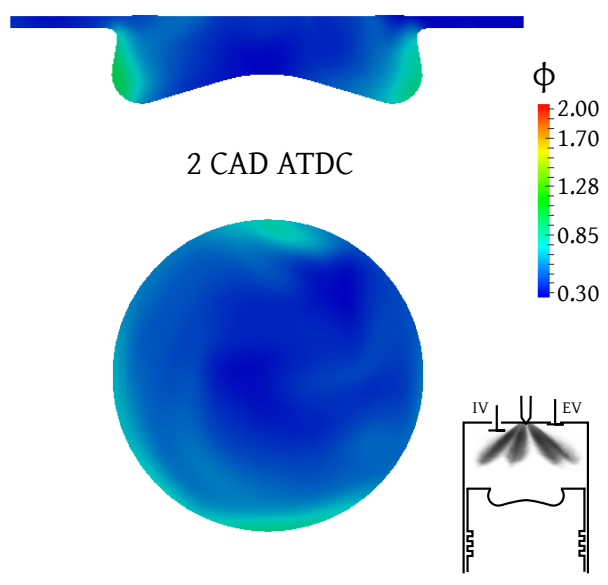

LN

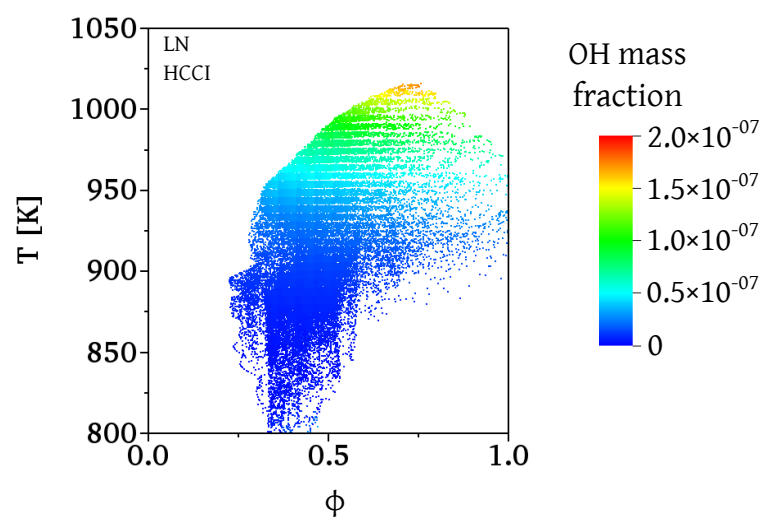

Figure 5: Comparison of equivalence ratio (side- and top-views (section AA)) and color coded $\mathrm{OH}$ mass fraction in T- $\phi$ map for PRF 65 (left panels) and LN (right panels) for HCCI case at the onset of ignition.

Next, PPCI conditions were studied for three different SOIs. The following discussion draws extensively from the conceptual models presented by Musculus et al. [3] for low temperature PPCI combustion of diesel fuels. However, our observations of mixing and combustion are different due to the lower boiling point range and lower cetane numbers of naphtha fuels compared to diesel fuel; the final BPs of typical diesel and $\mathrm{LN}$ are 673 and $360 \mathrm{~K}$, respectively, while the derived cetane numbers of typical diesel and $\mathrm{LN}$ are 56.7 and 36.3, respectively. 
Figure 6 shows the amount of fuel required for various SOIs to achieve the same CA5o value at 4 CAD ATDC. It is to be noted that during this the IMEP does not remain fixed as observed in Table 4 Compared to other injection timings, for the SOI of 35 CAD BTDC case required more fuel mass due to the non-uniform mixture distribution. The in-cylinder temperatures are still low, so a significant amount of the fuel reaches the colder squish regions, while the bulk mixture is leaner than under HCCI conditions. This was confirmed by the unburned hydrocarbon (UHC) analysis of exhaust gas shown in Fig. 7 and also the simulation results (as discussed later). Therefore, more fuel is needed to compensate for the leaner bulk mixtures. Beyond 35 CAD BTDC, however, the required fuel mass was found to decrease as SOI was delayed. This is because higher in-cylinder temperatures promote vaporization and in-cylinder fuel distribution, thereby creating stratified locally rich mixtures that promote autoignition. This tendency becomes enhanced from 35 to 19 CAD BTDC. At 19 CAD BTDC, the fuel consumption rates are even smaller than those for the HCCI cases for LN and PRF 65 (cf. Table 4).

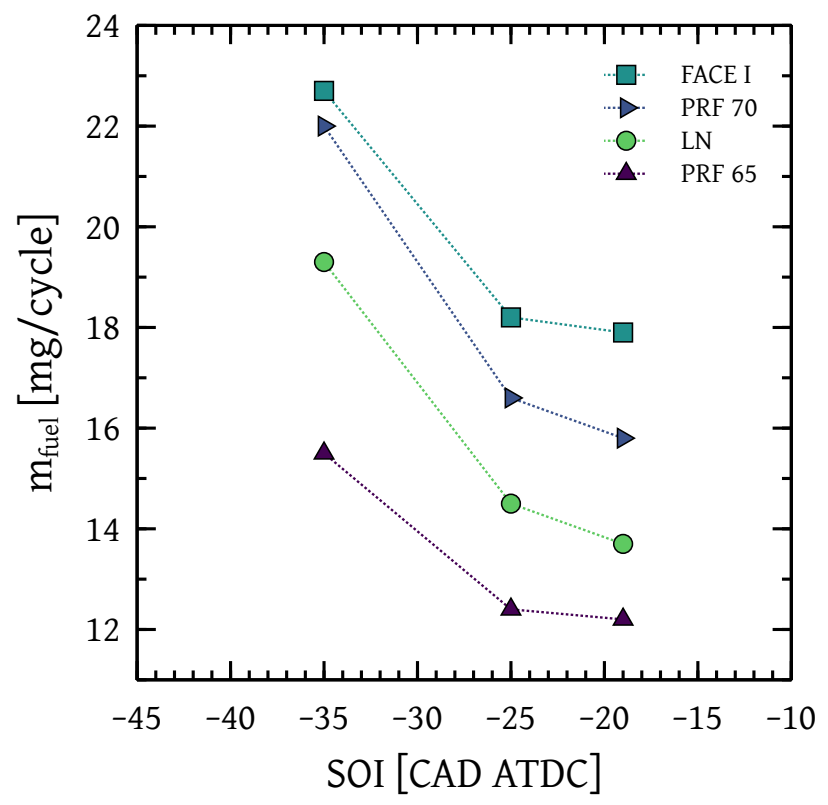

Figure 6: Fuel consumption rate with injection timing in PPCI mode.

The effects of fuel type are also more pronounced at later SOI conditions. For example, for injection at 35 CAD BTDC, the difference between the PRF 65 and PRF 70 curves approximately represents the chemical effects resulting from a RON difference of 5. This implies that autoignition becomes more sensitive to low-temperature fuel chemistry at later SOI, where rich pockets ignite first. The effects of fuel RON become more important in richer mixtures because low temperature reaction kinetics is sensitive to the concentration and chemical nature (i.e., reactivity) of the fuel radicals present 
[51]. In addition, the distinct physical properties also start to play a role in determining the combustion behavior at later injection timings. For the injection at 35 CAD BTDC, the difference between the LN and PRF 65 cases is found to be significantly larger than the difference between the FACE I and PRF 70. This can be attributed to larger volatility differences in the LN/PRF 65 pair.

In addition, the majority of the fuel enters the squish region and leads to increased UHC emissions, as shown in Fig. 7. An increased level of UHC was observed at earlier PPCI injection cases and gradually reduced with later injections; the increase in UHC for advanced injection timings could be attributed to splash on the liner or fuel entering the squish region. CFD simulations (shown later) confirmed that major source of UHC is fuel entering the squish regions (and not splash on the liner). The role of liquid properties on ignition characteristics increases for the less reactive fuels (PRF 70 and FACE I) under later injection timings (e.g., 19 and 25 CAD BTDC) because fuel vaporization and mixing largely control where rich pockets are formed and ignite.

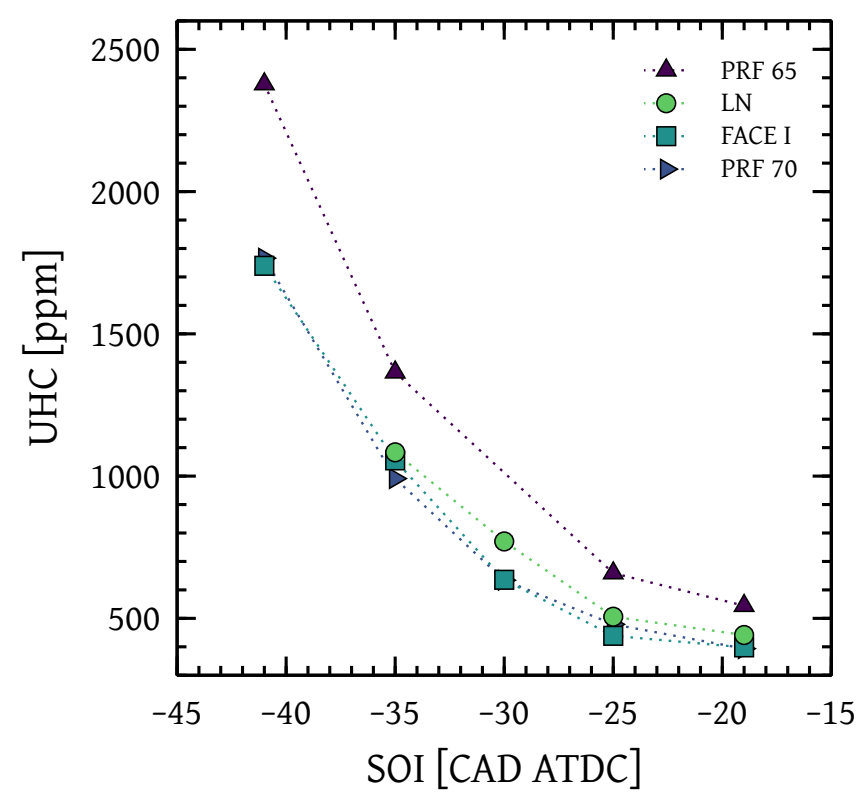

Figure 7: Variation of unburned hydrocarbon emission with SOI for different fuels.

In the above parametric study, different amounts of each fuel were required to maintain the same CA50. Alternatively, it is also practically relevant to understand the effect on $\mathrm{CA}_{50}$ with same mass injected for the different fuels. As a reference, the mass of PRF 65 required to maintain a constant value of CA5o fixed at 4 CAD ATDC was obtained, as shown in Fig. 8, over a wide range of injection timings ranging from HCCI to PPCI conditions. As injection timing was progressively retarded from 130 to 65 CAD BTDC, the amount of PRF 65 required steadily increases due to fuel entering the squish region. Further delay in injection timing requires less amounts of 
fuel because the injected fuel now enters engine bowl. This improves fuel/air mixing and creates fuel rich pockets with the right equivalence ratio to advance ignition.

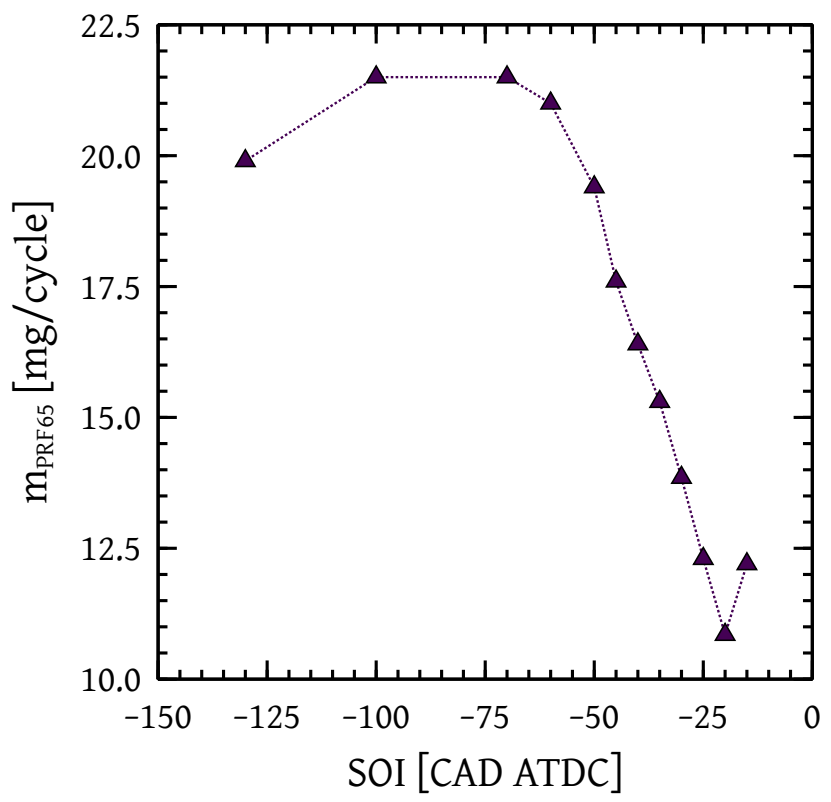

Figure 8: Mass of PRF 65 required with SOI to maintain constant CA50 of 4 CAD ATDC.

When the matching amount of other fuels was injected at the same injection timings, a variation in $\mathrm{CA}_{50}$ was observed, as shown in Fig. 9a,the error bars indicate standard deviation in CA50. The PRF 65 data is represented as the horizontal line due to the imposed condition of $\mathrm{CA}_{50}$ set at 4 CAD ATDC. The observed variations in $\mathrm{CA}_{50}$ for the rest of fuels are non-monotonic. The simulations performed for these experiments were also able to capture similar trends that were observed experimentally. The variation of simulated $\mathrm{CA}_{50} \mathrm{O}$ at different $\mathrm{SOI}$ are shown in Fig. $9 \mathrm{~b}$. At early injection timings, the $\mathrm{CA}_{50}$ values are similar for all the fuels. A small difference in $\mathrm{CA}_{50}$ is observed when comparing the RON 65 pair (LN/PRF 65) to the RON 70 pair (FACE I/PRF 70) of fuels. However, as the injection timing was retarded, differences in combustion phasing were observed between the fuel pairs. Again, the differences in $\mathrm{CA}_{50} \mathrm{O}$ values between RON 65 and RON 70 fuels increase as the injection timing is retarded. The lower octane fuels have earlier CA50 values due to their higher chemical reactivity; these differences are magnified at later SOI because ignition reactivity is more sensitive to fuel chemical kinetics (i.e., RON) in the rich pockets where autoignition occurs. In addition, differences in $\mathrm{CA}_{50}$ values are also observed within a pair of fuels. This can be attributed to differences in physical properties, such as volatility characteristics and surface tension. 

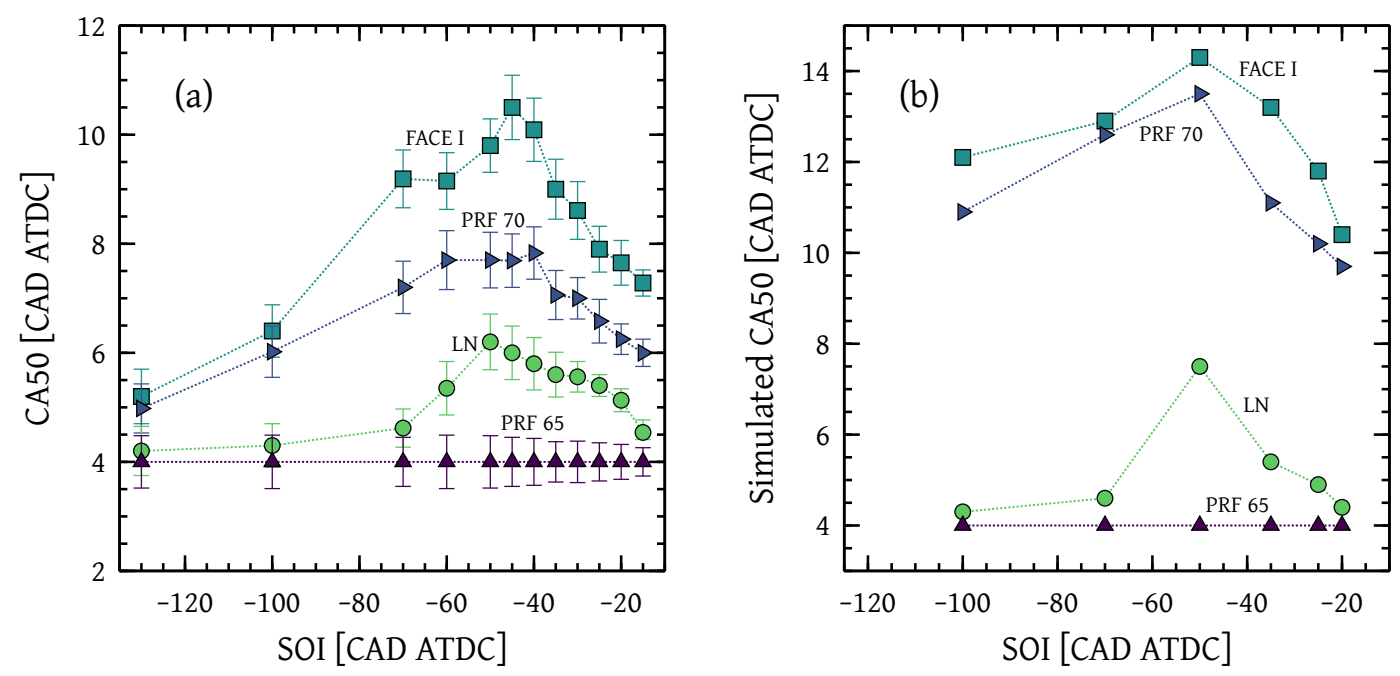

Figure 9: Variation of $\mathrm{CA}_{50}$ (a) experiments (b) simulations at different SOI when all fuels were injected with mass of PRF 65 at respective SOI (cf. Fig. 8 )

Figure 10 shows the cylinder pressure and normalized heat release rates for SOI at 19 CAD BTDC with the first set of experimental conditions given in Table 4. The HRR under the PPCI conditions occurs over a shorter duration (i.e., fewer CA) compared to under the HCCI conditions (refer Fig. $4(\mathrm{~b})$. This can be attributed to the fact that later injection timings introduce the fuel to higher in-cylinder temperatures that expedite the ignition and combustion process. Figure 10 also shows that the maximum heat release (and peak pressures) was exhibited by FACE I and the minimum by PRF 65, which scales directly with the amount of the injected fuel mass. These features of PRF 65 are attributed to its physical and kinetic properties; when injected it forms richer pockets (compared to LN) that ignite earlier (compared to PRF 70).

Simulations to show differences in equivalence ratio distribution under HCCI and PPCI conditions were carried out. Figure 11 shows the difference between the in-cylinder equivalence ratio distributions for PRF 65 at 300 and 19 CAD BTDC. For brevity, these two conditions will be referred to as the HCCI and PPCI cases, respectively. Each case shows the instantaneous snapshot at the onset of ignition defined by the start of $\mathrm{OH}$ rise, which was 2 CAD ATDC for the HCCI and I CAD ATDC for the PPCI cases. In each case, two equivalence ratio $(\phi)$ contours are presented for side-view cross section (at centre) and top-views (section AA, shown in Fig. II) of the cylinder domain. For the HCCI case, the mixture is reasonably homogeneous with a maximum local equivalence ratio of 0.5 . For the PPCI case, on the other hand, fuel-rich pockets $(1<\phi<2)$ are observed primarily at the outer periphery of the engine bowl. The corresponding T- $\phi$ map and $\mathrm{OH}$ peaks (in color) show that the main ignition condition shifted from $\phi=0.5$ (HCCI) to $\phi=1.0$ (PPCI), thus explaining the enhanced reactivity 

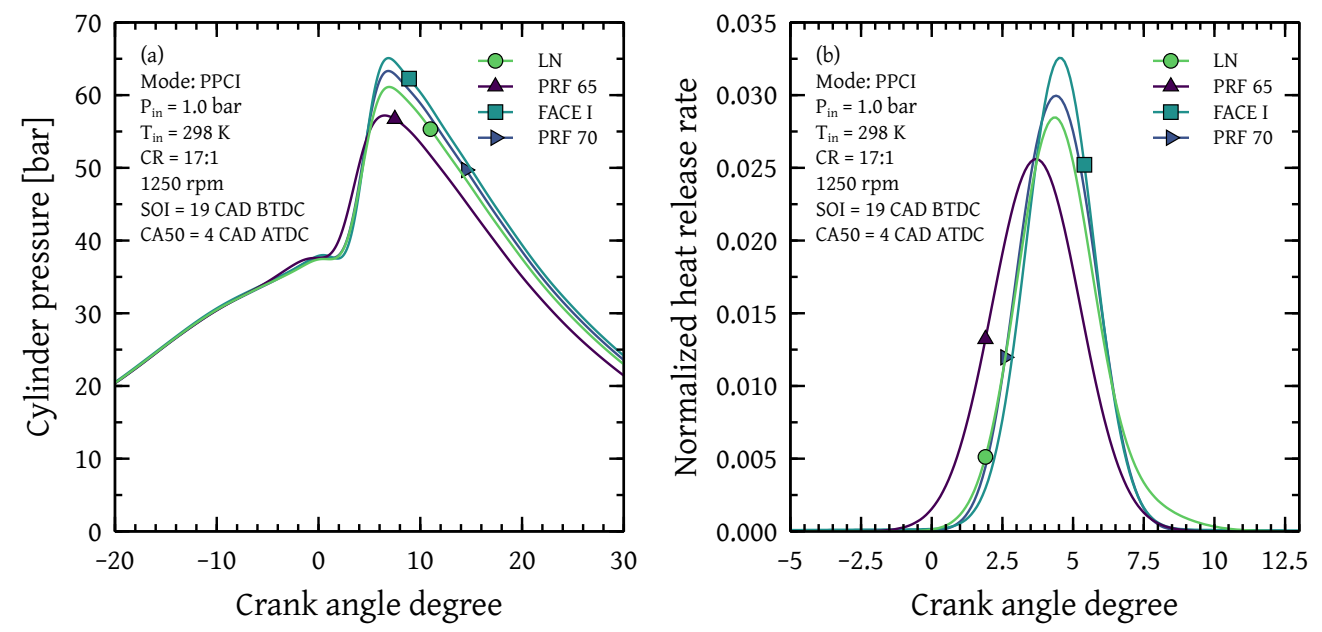

Figure 10: (a) Cylinder pressure traces and (b) normalized heat release rates for tested fuels in PPCI mode with SOI at 19 CAD BTDC at I CAD ATDC after the onset of ignition.

for the PPCI condition. As such, more fuel must be added in the HCCI case to match the combustion phasing with the PPCI case. Moreover, the equivalence ratio distribution in the side-view shows fuel-rich pockets in the piston bowls, indicating that ignition starts from these regions. 


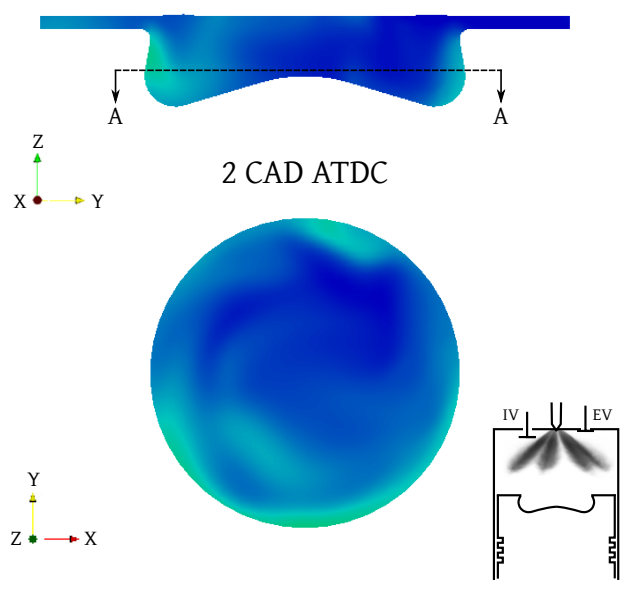

HCCI

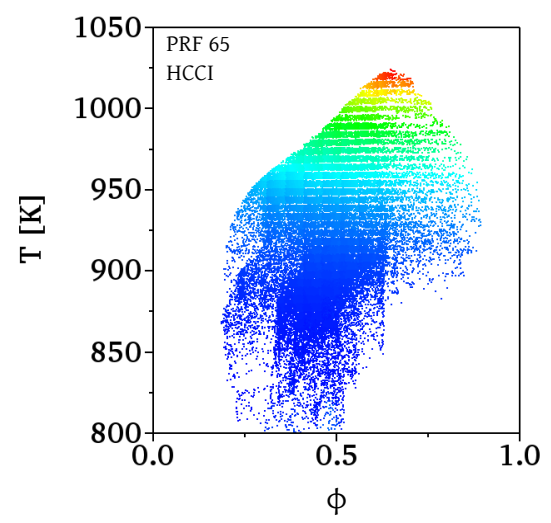

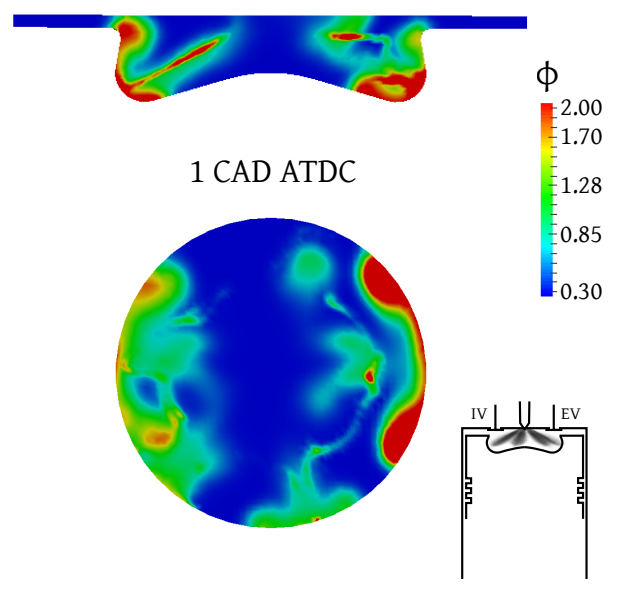

PPCI

(SOI 19 CAD BTDC)

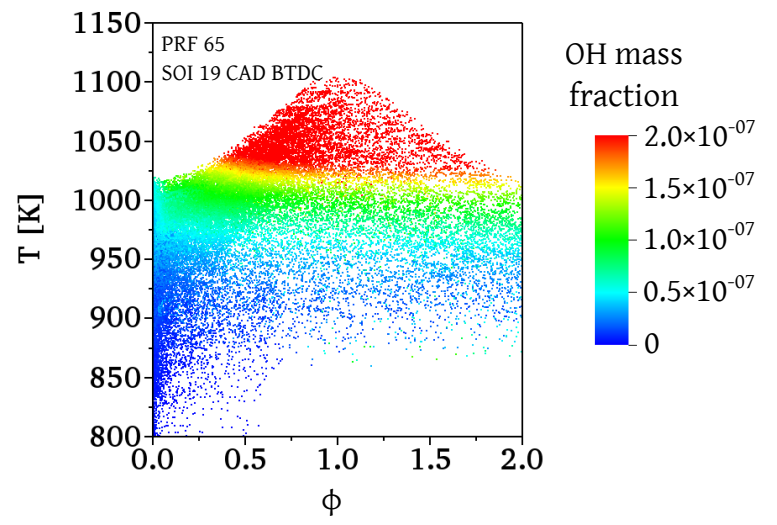

Figure 11: Comparison of equivalence ratio (side- and top-views (section AA)) and color coded $\mathrm{OH}$ mass fraction in T- $\phi$ map for HCCI (left panels) and PPCI modes with SOI at 19 CAD BTDC (right panels) for PRF 65. 


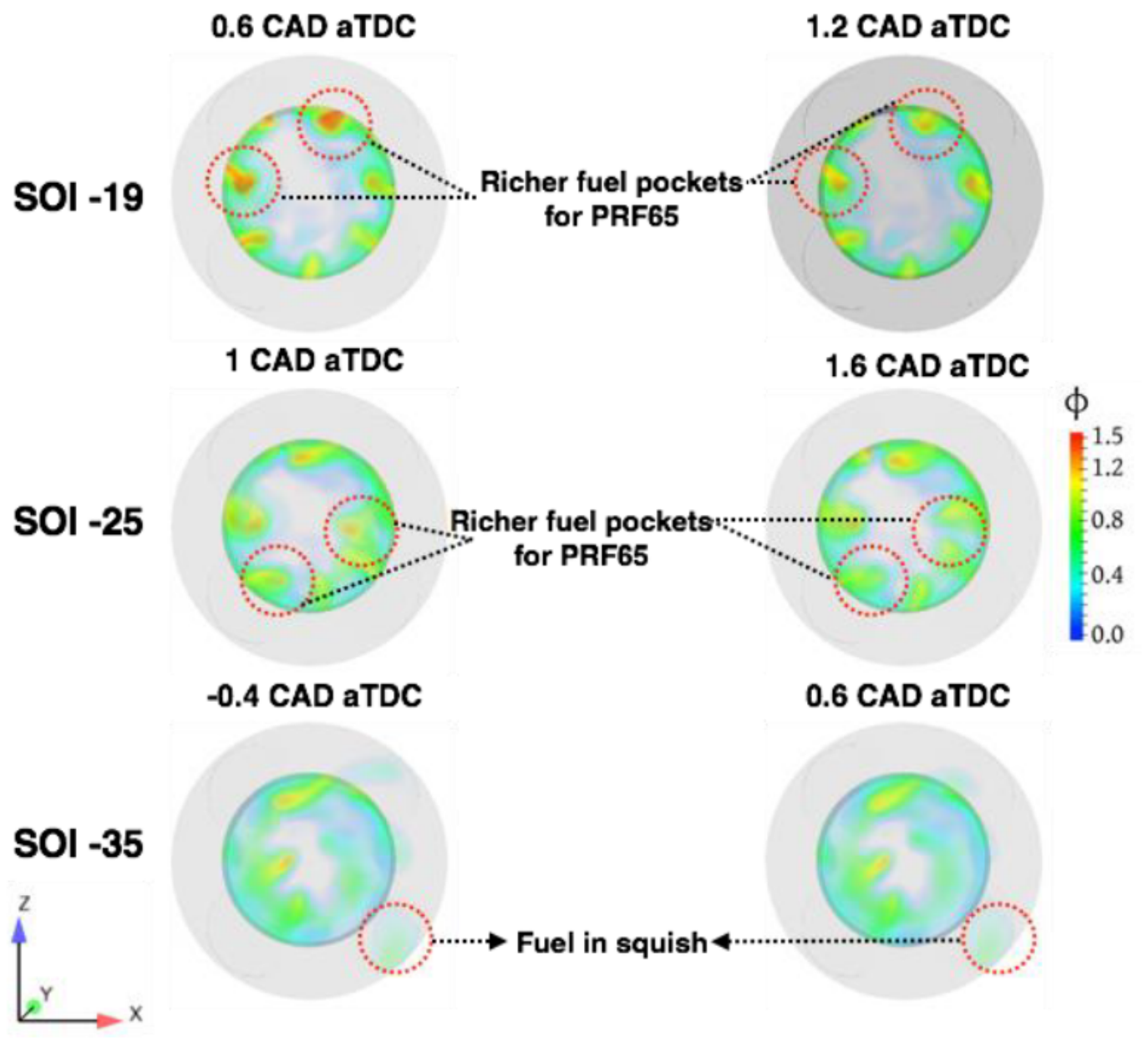

Figure 12: Comparison of volume rendering of equivalence ratio distribution for PRF 65 (left panels) and LN (right panels) at SOIs of 35, 25, 19 CAD BTDC.

Figure 12 shows the comparison of the volume rendering of equivalence ratio distribution in the piston bowl between PRF 65 and LN fuels under the PPCI conditions at SOIs of 35, 25 and 19 CAD BTDC obtained o.1 CAD before the onset of ignition. For each respective SOI and fuel, ignition is defined as the $\mathrm{CA}$ at which $\mathrm{OH}$ mole fraction reaches a maximum. Since for the same SOI, ignition occurs at different CAD due to fuel stratification created by differences in physical properties the volume rendering for a specified SOI is not at the same CAD, but rather at 0.1 CAD before the onset of ignition. Noticeable differences are evident between these two fuels, as indicated by the red circles in the figure. For SOI 35 CAD BTDC, appreciable amount of fuel enters the squish zone due to early injection, as seen in Fig. 12. Fuel entering the squish region has a high probability of eventually escaping as UHC emission during the exhaust stroke, which is in agreement with the experiments at the same injection timing, as 
shown in Fig. 7. Although the equivalence ratio distribution at SOI 35 CAD BTDC appears similar, the amount of LN fuel entering the squish region is higher than that of PRF 65, which results in increased fuel consumption of the former for the same CA5o. As injection timing is retarded, differences in equivalence ratio distribution are observed. More fuel is confined to the bowl at later injection timings.

A larger number of rich fuel-air pockets can be observed for PRF 65 compared to LN, given the same amount of fuel injected, which can be observed in Fig. 13 . Figure 13 shows the $T-\phi$ distribution color coded with $\mathrm{OH}$ mass fraction in the engine combustion chamber for SOI 35. The T- $\phi$ distribution with PRF 65 at the onset of ignition near 0.4 CAD BTDC is shown in Fig 13(a). In the case of LN, the mixture has not ignited as shown in Fig. 13(b). LN ignition occurs 1 CAD after PRF 65 corroborating earlier observations and the shift in CA50 with delay in injection timing. Similar observations are made for SOI 19 CAD BTDC. These observations are qualitative and specific to the cut-planes at which the contours are generated. 

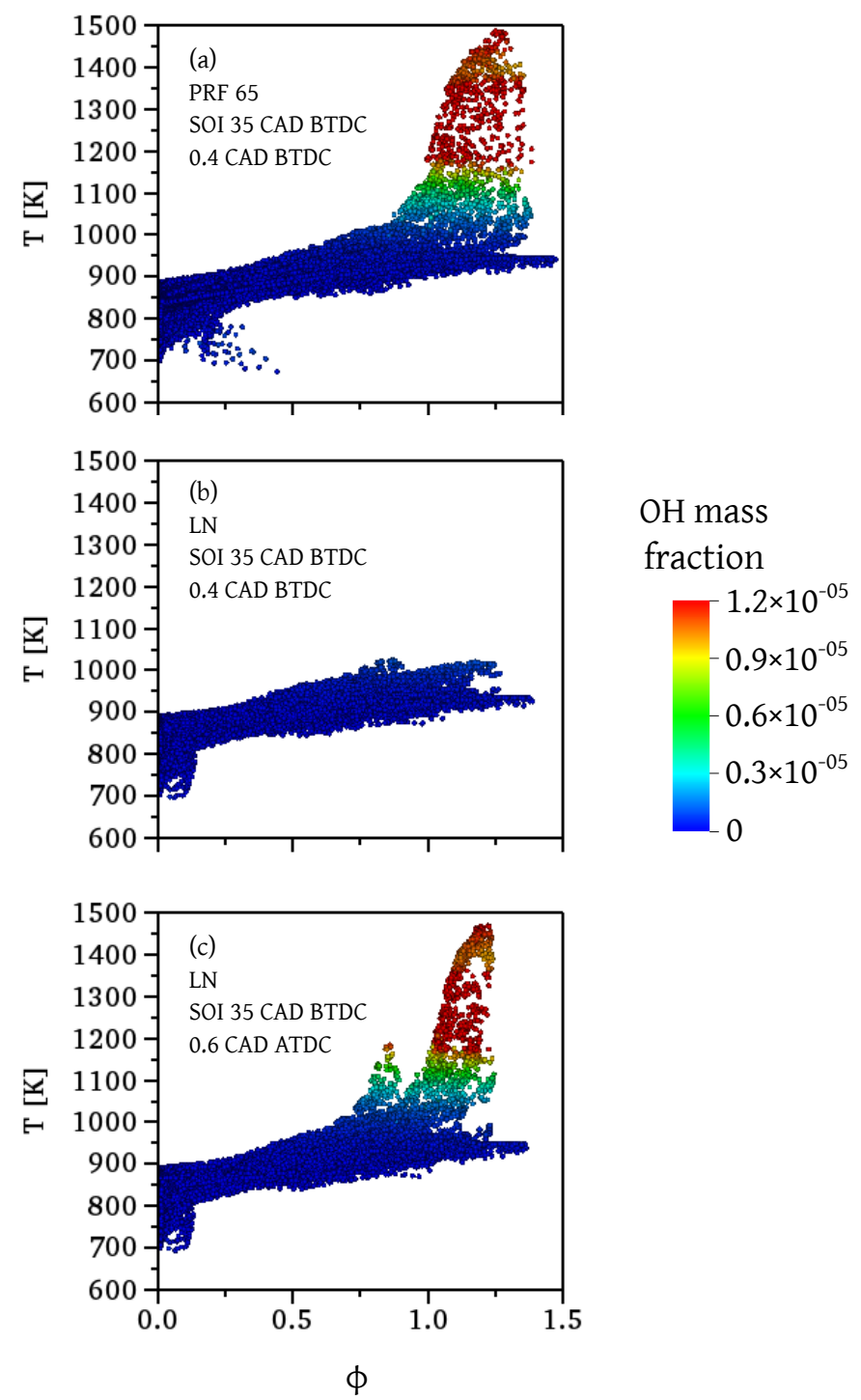

Figure 13: Comparison of T- $\phi$ color coded with $\mathrm{OH}$ mass fraction of (a) PRF 65 at onset of ignition (b) LN at the same CAD as of PRF 65 ignition (c) LN at onset of ignition with SOI 19 CAD BTDC.

For a quantitative analysis of the stratification levels, probability density functions (PDF) of equivalence ratio are calculated for all the fuels and given in Fig. 14. The PDF of equivalence ratio is calculated using the normal distribution with mean, $\mu$ and standard deviation, $\sigma$ as given in Eq. 2

$$
f\left(x ; \mu, \sigma^{2}\right)=\frac{1}{\sigma \sqrt{2 \pi}} e^{\frac{-(x-\mu)^{2}}{2 \sigma^{2}}}
$$



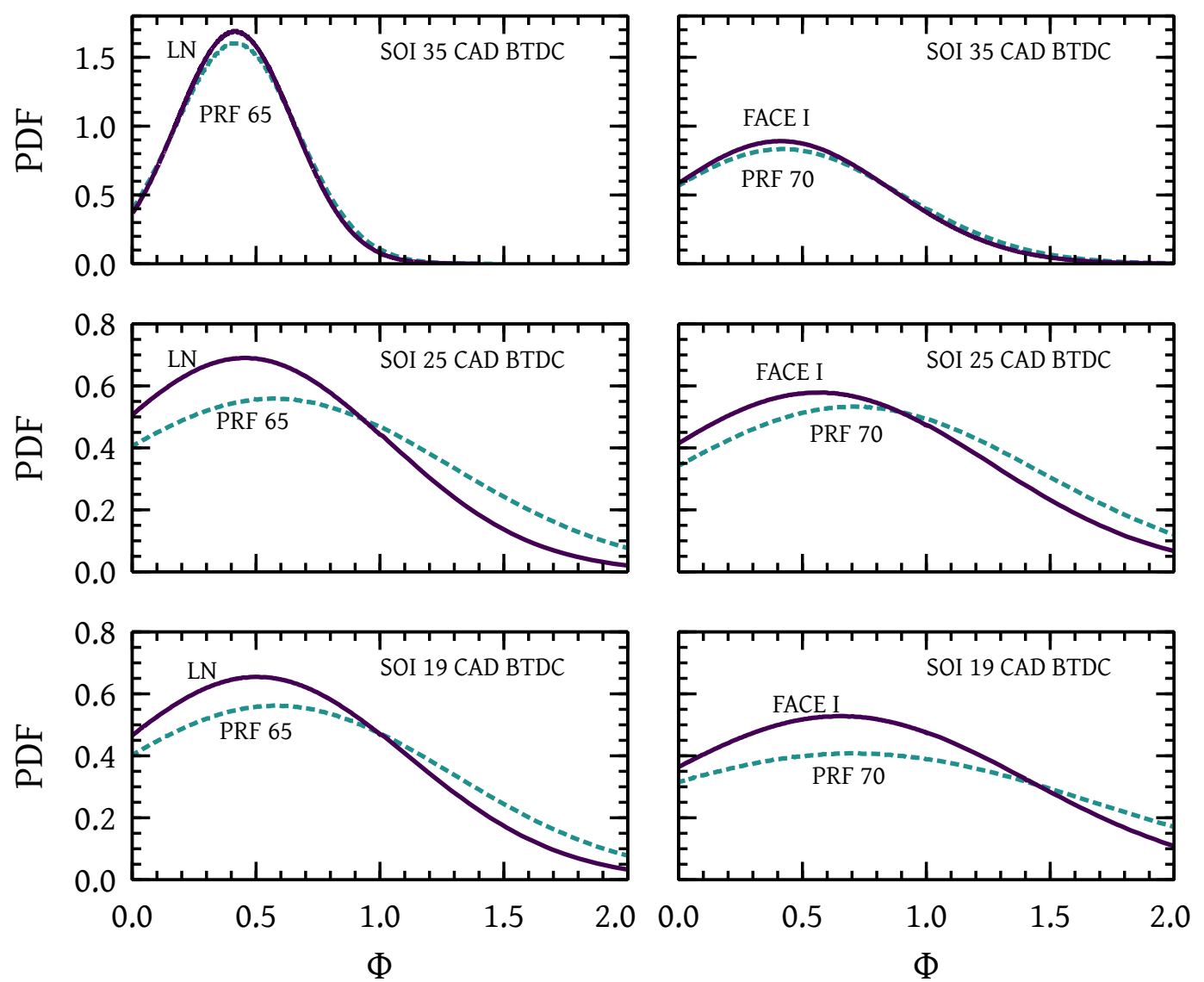

Figure 14: Comparison of probability density function of equivalence ratio of PRF 65 (dashed), LN (solid) (left panels) and PRF 70 (dashed), FACE I (solid) (right panels) at SOI at 35, 25, 19 CAD BTDC obtained o.1 CAD before onset of ignition for each respective $\mathrm{SOI}$ and fuel

From the PDF for late injection cases, it is clear that PRF 65 has a greater number of fuel-rich pockets $(\phi>2)$ that ignite earlier [4] compared to the leaner mixtures for LN. Considering that both fuels have identical kinetics, as shown previously under HCCI conditions, the difference in equivalence ratio distribution is attributed to physical property variations. LN is lighter and evaporates faster. Consequently, the liquid spray penetration distance becomes shorter such that it requires a shorter mixing time due to lower SMD to yield an overall leaner mixture distribution compared to PRF 65. This is clearly seen by the higher fuel concentration throughout the bowl region shown in the left panels for PRF 65 of Fig. 12. Again, consistent behavior was found for FACE I and PRF 70 (not shown). 

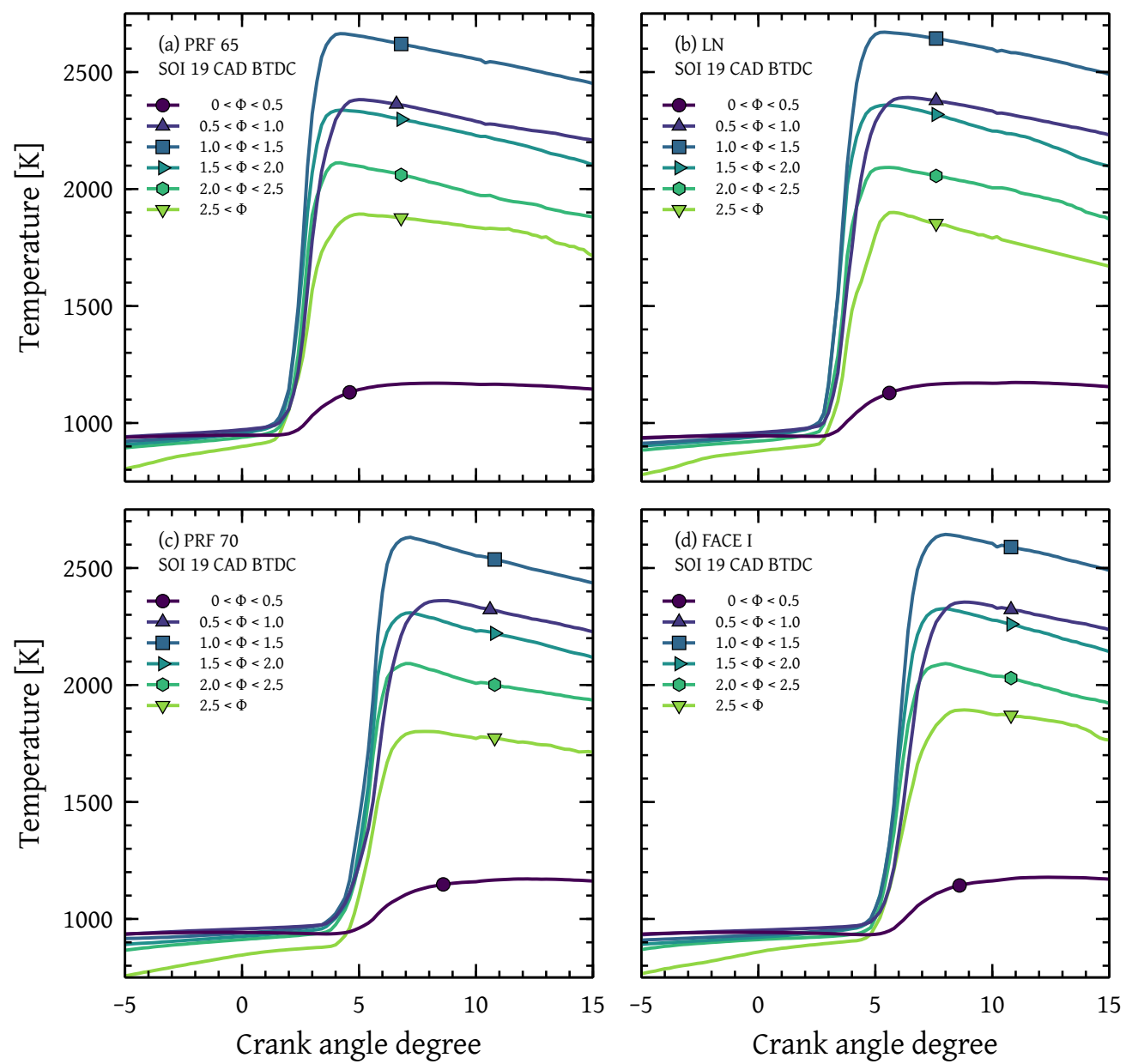

Figure 15: In-cylinder temperature variation with crank angle of various bins classified based on equivalence ratio for (a) PRF 65 (b) LN (c) PRF 70 (d) FACE I at SOI 19 CAD BTDC. 
Figure 15 shows the variation of in-cylinder temperature with crank angle of various bins classified based on equivalence ratio. From the figures, it can be concluded that independent of the fuel, the first temperature rise is always seen in the richer zones $(\phi>1)$, where ignition occurs [4] and then proceeds to ignite leaner zones [52] The zones with $\phi<1$ do not release heat initially and tends to ignite the latest. The temperatures from zones with $\phi<0.5$ are low when compared with other zones, indicating that these lean zones do not release enough heat even after ignition. The zones in the range of $1<\phi<1.5$ are highly reactive and ignite first, exhibiting a trend that is similar for all the fuels in the present study. In Fig. 15 (a) and (b), both PRF 65 and LN have similar trends but ignite at different crank angle for the same amount of fuel mass injected due to the reasons mentioned above. Consistent observations were made for PRF 70 and FACE I.
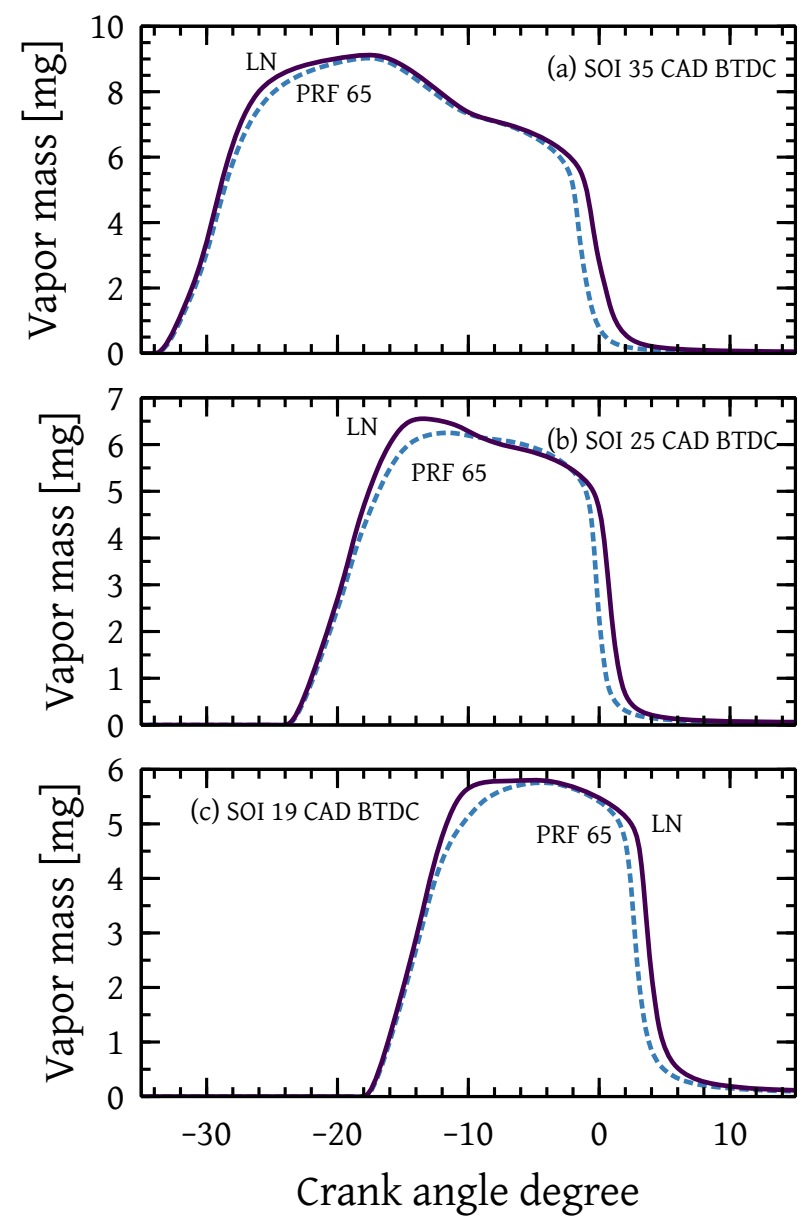

Figure 16: Mass of fuel vapor at different crank angles for PRF 65 (dashed) and LN (solid) at SOI (a) 35 (b) 25 (c) 19 CAD BTDC. 
Figure 16 shows the fuel vapor mass as a function of crank angle degree for the three late SOI cases for the LN/PRF 65 pair. The vapor mass is obtained from the spray output file obtained with CONVERGE ${ }^{\mathrm{TM}}$ that provides mass of fuel in both the liquid and gas phase separately. The results for the FACE I/PRF 7o pair also show the consistent behavior. It is evident that the differences in the physical properties between the fuel leads to a noticeable difference in the evaporation rate, which subsequently affects the mixture distribution observed in Fig. 12. For all SOI cases, note that LN is consumed later than PRF 65 despite the earlier vaporization behavior. Again, this is attributed to the longer ignition delay times associated with the low ON fuels; earlier vaporization and mixing yields an overall uniform and lean composition and hence lower reactivity. Standard diesel engine operations involve injection near TDC and the highly reactive diesel fuel (i.e., high cetane number) almost immediately reacts upon vaporization; therefore, the variations in the physical properties of the fuel would hardly affect the overall combustion behavior. These results demonstrate that the effects of the physical properties are more important for lower ON fuels utilizing earlier SOI operations in PPCI engines.

\section{CONCLUDING REMARKS}

Engine experiments were conducted to determine the effect of fuel physical and chemical kinetic properties on compression ignition of LN and FACE I gasoline and their respective PRF surrogates. HCCI tests demonstrated that all fuels show similar reactivity, which was attributed to similar chemical kinetics. However, under progressively later PPCI injection timings, more LN and FACE I were required to match the combustion phasing of their respective PRF surrogates. These trends were attributed to differences in physical properties, particularly volatility characteristics and surface tension, which change the in-cylinder mixture fraction distribution. LN has high volatility and lower surface tension leading to finer droplets, as shown in SMD calculations, which leads to early mixing and leaner fuel distribution in the engine cylinder when compared to the relatively less volatile fuels, i.e., FACE I and PRF surrogates.

The experimental observations were supported by numerical simulations that considered realistic chemical kinetic and physical properties for the different fuels tested, while modeling their gas-phase combustion with PRF kinetics. Contours of equivalence ratio distribution in the engine cylinder showed more rich fuel-air pockets existed for PRF 65 compared to LN when the same mass of fuel was injected, elucidating the influence of liquid properties on fuel stratification for late injection cases. The same trends were observed for PRF 70 and FACE I. These observations were verified quantitatively with PDF of equivalence ratio and vapor mass variation at various times during the injection event. In less volatile fuels, a larger number of rich pockets advanced ignition, which eventually triggered the main heat release. 
The results presented herein elucidate the influence of fuel physical properties on fuel-air distribution and ignition characteristics. The present work concludes that primary reference fuels are suitable surrogates for low octane fuels under the HCCI conditions studied herein. However, surrogates with accurate physical properties are needed to emulate fuel stratification and combustion characteristics of low octane naphtha blends under the partially premixed engine combustion conditions investigated in this paper. All the engine experiments were conducted at an injection pressure of 300 bar, which is lower than typical diesel engine injection pressures. In addition the study was limited to low speed and low load conditions. The conclusions obtained in this study should be further examined in engine tests comprising more fuel mixtures, a wider range of injection pressures, and various speeds and loads.

\section{ACKNOWLEDGMENTS}

This work was supported by Saudi Aramco under the FUELCOM program and the Clean Combustion Research Center (CCRC) at King Abdullah University of Science and Technology (KAUST). This work was supported by Saudi Aramco under the FUELCOM program and the Clean Combustion Research Center (CCRC) at King Abdullah University of Science and Technology (KAUST). The authors are thankful to Yoann Viollet at the Saudi Aramco Fuel Technology Division for helpful comments in improving the manuscript. We are also grateful to Adrian Ichim at the Clean Combustion Research Center, KAUST for his help and support with the engine experiments. 


\section{REFERENCES}

[1] G. T. Kalghatgi, The outlook for fuels for internal combustion engines, International Journal of Engine Research 15 (4) (2014) 383-398. doi:10.1177/ 1468087414526189 .

[2] G. T. Kalghatgi, Developments in internal combustion engines and implications for combustion science and future transport fuels, Proceedings of the Combustion Institute 35 (1) (2015) 101-115. doi:10.1016/j.proci.2014.10.002.

[3] M. P. B. Musculus, P. C. Miles, L. M. Pickett, Conceptual models for partially premixed low-temperature diesel combustion, Progress in Energy and Combustion Science 39 (2) (2013) 246-283. doi:10.1016/j.pecs.2012.09.001.

[4] N. Shimazaki, T. Tsurushima, T. Nishimura, Dual mode combustion concept with premixed diesel combustion by direct injection near top dead center, SAE Technical Paper 2003-01-0742. doi:10.4271/2003-01-0742.

[5] L. Hildingsson, G. Kalghatgi, N. Tait, B. Johansson, A. Harrison, Fuel octane effects in the partially premixed combustion regime in compression ignition engines, SAE Technical Paper 2009-01-2648. doi:10.4271/2009-01-2648.

[6] V. Manente, B. Johansson, W. Cannella, Gasoline partially premixed combustion, the future of internal combustion engines?, International Journal of Engine Research 12 (3) (2011) 194-208. doi:10.1177/1468087411402441.

[7] S. Ciatti, S. N. Subramanian, An experimental investigation of low-octane gasoline in diesel engines, Journal of Engineering for Gas Turbines and Power 133 (9) (2011) 092802. doi:10.1115/1.4002915.

[8] J. Chang, G. Kalghatgi, A. Amer, Y. Viollet, Enabling high efficiency direct injection engine with naphtha fuel through partially premixed charge compression ignition combustion, SAE Technical Paper 2012-01-0677. doi:10.4271/2012-01-0677

[9] J. Chang, Y. Viollet, A. Amer, G. Kalghatgi, Fuel economy potential of partially premixed compression ignition (PPCI) combustion with naphtha fuel, SAE Technical Paper 2013-01-2701. doi:10.4271/2013-01-2701.

[10] H. Yang, S. Shuai, Z. Wang, J. Wang, H. Xu, Performance of straight-run naphtha single-and two-stage combustion modes from low to high load, International Journal of Engine Research 14 (5) (2013) 469-478. doi:10.1177/1468087413488113.

[11] K. Kim, Z. Wang, B. Wang, S. Shuai, H. Yang, C. Bae, Load expansion of naphtha multiple premixed compression ignition (MPCI) and comparison with partially premixed compression ignition (PPCI) and conventional diesel combustion (CDC), Fuel 136 (2014) 1-9. doi:10.1177/1468087413488113. 
[12] W. Cannella, M. Foster, G. Gunter, W. Leppard, FACE gasolines and blends with ethanol: detailed characterization of physical and chemical properties (2014). URL http://www.crcao.com/reports/recentstudies2014/AVFL-24/AVFL-24\% 20FACE\%20Gasolines\%20Report\%20-\%20071414.pdf

[13] ASTM D2699-13b, Standard test method for research octane number of sparkignition engine fuel, ASTM Internationaldoi:10.1520/D2699

[14] ASTM D2700-16, Standard test method for motor octane number of spark-ignition engine fuel, ASTM Internationaldoi:10.1520/D2700-16.

[15] G. T. Kalghatgi, Auto-ignition quality of practical fuels and implications for fuel requirements of future SI and HCCI engines, SAE Technical Paper 2005-01-0239. doi:10.4271/2005-01-0239.

[16] M. Mehl, J.-Y. Chen, W. J. Pitz, S. M. Sarathy, C. K. Westbrook, An approach for formulating surrogates for gasoline with application toward a reduced surrogate mechanism for CFD engine modeling, Energy \& Fuels 25 (11) (2011) 5215-5223. doi:10.1021/ef201099y.

[17] S. M. Sarathy, G. Kukkadapu, M. Mehl, T. Javed, A. Ahmed, N. Naser, A. Tekawade, G. Kosiba, M. AlAbbad, E. Singh, S. Park, M. Al Rashidi, S. H. Chung, W. L. Roberts, M. A. Oehlschlaeger, C.-J. Sung, A. Farooq, Compositional effects on the ignition of FACE gasolines, Combustion and Flamedoi:10.1016/j.combustflame. 2016.04 .010 .

[18] G. Kalghatgi, L. Hildingsson, A. Harrison, B. Johansson, Surrogate fuels for premixed combustion in compression ignition engines, International Journal of Engine Research (2011) 1468087411409307doi:10.1177/1468087411409307.

[19] G. Kalghatgi, H. Babiker, J. Badra, A simple method to predict knock using toluene, iso-octane, $\mathrm{n}$-heptane blends (TPRF) as gasoline surrogates, SAE International Journal of Engines 7 (2015) 663-672. doi:10.4271/2015-01-0757.

[20] J. A. Badra, N. Bokhumseen, N. Mulla, S. M. Sarathy, A. Farooq, G. Kalghatgi, P. Gaillard, A methodology to relate octane numbers of binary and ternary nheptane, iso-octane and toluene mixtures with simulated ignition delay times, Fuel 160 (2015) 458-469. doi:10.1016/j.fuel.2015.08.007.

[21] T. Javed, E. F. Nasir, A. Ahmed, J. Badra, K. Djebbi, M. Beshir, W. Ji, S. M. Sarathy, A. Farooq, Ignition delay measurements of light naphtha: A fully blended low octane fuel, Proceedings of the Combustion Institute 36 (1) (2017) 315-322. doi:10.1016/j.proci.2016.05.043. 
[22] V. S. B. Shankar, M. Sajid, K. Al-Qurashi, N. Atef, I. Alkhesho, A. Ahmed, S. Chung, W. Roberts, K. Morganti, M. Sarathy, Primary reference fuels (PRFs) as surrogates for low sensitivity gasoline fuels, SAE Technical Paper 2016-01-0748. doi:10.4271/ 2016-01-0748.

[23] G. Haraldsson, P. Tunestål, B. Johansson, J. Hyvönen, HCCI combustion phasing in a multi cylinder engine using variable compression ratio, SAE Technical Paper 2002-01-2858. doi:10.4271/2002-01-2858.

[24] J. Hyvönen, G. Haraldsson, B. Johansson, Operating range in a multi cylinder HCCI engine using variable compression ratio, SAE Technical Paper 2003-01-1829. doi:10.4271/2003-01-1829.

[25] T. W. Ryan, T. J. Callahan, D. Mehta, HCCI in a variable compression ratio engineeffects of engine variables, SAE Technical Paper 2004-01-1971. doi:10.4271/ 2004-01-1971.

[26] J. E. Dec, M. Sjöberg, Isolating the effects of fuel chemistry on combustion phasing in an HCCI engine and the potential of fuel stratification for ignition control, SAE Technical Paper 2004-01-0557. doi:10.4271/2004-01-0557.

[27] S. Saxena, I. D. Bedoya, Fundamental phenomena affecting low temperature combustion and HCCI engines, high load limits and strategies for extending these limits, Progress in Energy and Combustion Science 39 (5) (2013) 457-488. doi:10.1016/j.pecs.2013.05.002.

[28] M. Sjöberg, J. E. Dec, Smoothing HCCI heat-release rates using partial fuel stratification with two-stage ignition fuels, SAE Technical Paper 2006-01-0629. doi:10.4271/2006-01-0629.

[29] Y. Yang, J. E. Dec, N. Dronniou, M. Sjöberg, W. Cannella, Partial fuel stratification to control HCCI heat release rates: fuel composition and other factors affecting pre-ignition reactions of two-stage ignition fuels, SAE International Journal of Engines 4 (2011-01-1359) (2011) 1903-1920. doi:10.4271/2011-01-1359.

[30] Y. Yang, J. E. Dec, N. Dronniou, M. Sjöberg, Tailoring HCCI heat-release rates with partial fuel stratification: Comparison of two-stage and single-stage-ignition fuels, Proceedings of the Combustion Institute 33 (2) (2011) 3047-3055. doi: $10.1016 / j$.proci.2010.06.114.

[31] M. Wang, S. Gao, C.-F. Lee, An efficient and unified combustion model for cfd of si and ci engine operation, Tech. rep., SAE Technical Paper (2017). doi:10.4271/ 2017-01-0572. 
[32] D. Bradley, R. A. Head, Engine autoignition: The relationship between octane numbers and autoignition delay times, Combustion and Flame 147 (3) (2006) 171-184. doi:10.1016/j.combustflame.2006.09.001.

[33] M. Mehl, T. Faravelli, F. Giavazzi, E. Ranzi, P. Scorletti, A. Tardani, D. Terna, Detailed chemistry promotes understanding of octane numbers and gasoline sensitivity, Energy \& fuels 20 (6) (2006) 2391-2398. doi:10.1021/ef060339s.

[34] G. T. Kalghatgi, Fuel/engine interactions, SAE Internationaldoi:10.4271/R-409.

[35] J. L. Burger, N. Schneider, T. J. Bruno, Application of the advanced distillation curve method to fuels for advanced combustion engine gasolines, Energy \& Fuels 29 (7) (2015) 4227-4235. doi:10.1021/acs .energyfuels.5b00749.

[36] K. J. Morganti, A study of the knock limits of liquefied petroleum gas (lpg) in spark-ignition engines, Ph.D. thesis (2013). URL http://cat.lib.unimelb.edu .au/record=b5321566

[37] K. J. Richards, P. K. Senecal, E. Pomraning, CONVERGE (v2.2.o), convergent science, Inc., Madison, WI.

[38] A. Babajimopoulos, D. N. Assanis, D. L. Flowers, S. M. Aceves, R. P. Hessel, A fully coupled computational fluid dynamics and multi-zone model with detailed chemical kinetics for the simulation of premixed charge compression ignition engines, International journal of engine research 6 (5) (2005) 497-512. doi:10. $1243 / 146808705 \times 30503$.

[39] Y.-D. Liu, M. Jia, M.-Z. Xie, B. Pang, Development of a new skeletal chemical kinetic model of toluene reference fuel with application to gasoline surrogate fuels for computational fluid dynamics engine simulation, Energy \& Fuels 27 (8) (2013) 4899-4909. doi:10.1021/ef4009955

[40] M. Mehl, W. J. Pitz, C. K. Westbrook, H. J. Curran, Kinetic modeling of gasoline surrogate components and mixtures under engine conditions, Proceedings of the Combustion Institute 33 (1) (2011) 193-200. doi:10.1016/j.proci.2010.05.027.

[41] J. C. Beale, R. D. Reitz, et al., Modeling spray atomization with the kelvinhelmholtz/rayleigh-taylor hybrid model, Atomization and sprays 9 (6) (1999) 623-65o. doi:10.1615/AtomizSpr.v9.i6.40.

[42] N. Frössling, The evaporation of falling drops, Gerlands Beiträge zur Geophysik 52 (1938) 170.

[43] P. J. O'Rourke, Statistical properties and numerical implementation of a model for droplet dispersion in a turbulent gas, Journal of Computational Physics 83 (2) (1989) 345-36o. doi:10.1016/0021-9991(89)90123-X. 
[44] J. Cha, S. Y. Yang, N. Naser, A. I. Ichim, S. H. Chung, High pressure and split injection strategies for fuel efficiency and emissions in DI diesel engine, SAE Technical Paper 2015-01-1823. doi:10.4271/2015-01-1823.

[45] J. Kodavasal, C. P. Kolodziej, S. A. Ciatti, S. Som, Computational fluid dynamics simulation of gasoline compression ignition, Journal of Energy Resources Technology 137 (3). doi:10.1115/1.4029963.

[46] A. A. Amsden, P. J. O'rourke, T. D. Butler, KIVA-II: A computer program for chemically reactive flows with sprays.

[47] L. M. Pickett, C. L. Genzale, G. Bruneaux, L.-M. Malbec, L. Hermant, C. Christiansen, J. Schramm, Comparison of diesel spray combustion in different hightemperature, high-pressure facilities, SAE International Journal of Engines 3 (2010o1-2106) (2010) 156-181. doi:10.4271/2010-01-2106.

[48] A. Ahmed, M. Khurshid, N. Naser, J. Badra, P. Gaillard, S.-H. Chung, W. L. Roberts, S. M. Sarathy, Surrogate fuel formulation for light naphtha combustion in advanced combustion engines, in: Proceedings of the European Combustion Meeting 2015, 2015.

URL http://repository.kaust.edu.sa/kaust/handle/10754/581489

[49] K. Anand, Y. Ra, R. Reitz, B. Bunting, Surrogate model development for fuels for advanced combustion engines, Energy \& Fuels 25 (4) (2011) 1474-1484. doi: 10.1021/ef101719a.

[5o] S. M. Sarathy, G. Kukkadapu, M. Mehl, W. Wang, T. Javed, S. Park, M. A. Oehlschlaeger, A. Farooq, W. J. Pitz, C.-J. Sung, Ignition of alkane-rich FACE gasoline fuels and their surrogate mixtures, Proceedings of the Combustion Institute 35 (1) (2015) 249-257. doi:10.1016/j.proci.2014.05.122

[51] J. Zádor, C. A. Taatjes, R. X. Fernandes, Kinetics of elementary reactions in lowtemperature autoignition chemistry, Progress in energy and combustion science 37 (4) (2011) 371-421. doi:10.1016/j.pecs.2010.06.006

[52] J. E. Dec, Advanced compression-ignition enginesunderstanding the in-cylinder processes, Proceedings of the combustion institute 32 (2) (2009) 2727-2742. doi: $10.1016 / j$.proci.2008.08.008. 


\section{SUPPLEMENTARY MATERIAL}

Table $\mathrm{S}_{1}$ lists the engine-out emissions and exhaust back pressure of the first set of experiments.

Table S1: Engine-out emissions for first set of experiments (cf. Table 4 ).

\begin{tabular}{lccccc}
\hline Fuel & SOI (CAD bTDC) & $\mathrm{CO}_{2}(\mathrm{ppm})$ & $\mathrm{CO}(\mathrm{ppm})$ & $\mathrm{NO}_{\mathrm{x}}(\mathrm{ppm})$ & $\mathrm{UHC}(\mathrm{ppm})$ \\
\hline LN & & 33609.7 & 4367.3 & 1.9 & 1799.7 \\
PRF 65 & \multirow{2}{*}{300} & 34589.9 & 4109.2 & 2.2 & 1997.0 \\
FACE I & & 36713.9 & 3545.7 & 4.0 & 1876.3 \\
PRF 70 & 36041.6 & 3629.8 & 4.2 & 1803.9 \\
\hline LN & & 40424.0 & 4448.2 & 150.1 & 1083.5 \\
PRF 65 & 35 & 30340.8 & 5776.7 & 100.7 & 1364.9 \\
FACE I & & 47309.0 & 3816.4 & 218.8 & 1055.3 \\
PRF 70 & & 38822.7 & 5063.7 & 277.6 & 1765.9 \\
\hline LN & & 39468.5 & 1675.4 & 247.0 & 505.7 \\
PRF 65 & 25 & 32024.0 & 2445.6 & 120.8 & 658.9 \\
FACE I & & 43938.8 & 1290.8 & 483.7 & 438.6 \\
PRF 70 & & 41850.7 & 1548.8 & 334.7 & 479.0 \\
\hline LN & & 40775.1 & 1437.2 & 594.2 & 441.4 \\
PRF 65 & \multirow{2}{*}{19} & 34409.6 & 1838.5 & 390.7 & 544.3 \\
FACE I & & 46193.1 & 1098.6 & 989.0 & 398.0 \\
PRF 70 & & 44406.4 & 1180.7 & 837.6 & 393.6 \\
\hline
\end{tabular}

Table S2: Engine experimental test conditions for second set of experiments with LN.

\begin{tabular}{cccccc}
\hline SOI (CAD bTDC) & $\dot{m}_{\text {fuel }}(\mathrm{mg} /$ cycle $)$ & IMEP $($ bar $)$ & $\lambda$ & $R_{\max }(\mathrm{bar} / \mathrm{deg})$ & COV $(\%)$ \\
\hline 130 & 19.9 & 3.1 & 2.42 & 3.85 & 1.8 \\
100 & 21.5 & 3.0 & 2.11 & 3.45 & 2.4 \\
70 & 21.5 & 3.0 & 2.09 & 1.76 & 2.1 \\
60 & 21.0 & 2.9 & 2.23 & 1.97 & 2.8 \\
50 & 19.4 & 2.5 & 2.32 & 1.56 & 3.5 \\
45 & 17.6 & 2.1 & 2.49 & 1.61 & 3.4 \\
40 & 16.4 & 2.2 & 2.84 & 1.65 & 3.9 \\
35 & 15.3 & 2.2 & 2.96 & 1.83 & 2.5 \\
30 & 13.9 & 2.5 & 3.29 & 1.40 & 2.9 \\
25 & 12.3 & 2.8 & 3.84 & 2.46 & 1.9 \\
20 & 10.9 & 2.9 & 4.27 & 2.27 & 3.1 \\
15 & 12.2 & 3.1 & 3.67 & 6.34 & 2.7 \\
\hline
\end{tabular}


Table S3: Engine experimental test conditions for second set of experiments with FACE I.

\begin{tabular}{cccccc}
\hline SOI (CAD bTDC) & $\dot{m}_{\text {fuel }}(\mathrm{mg} /$ cycle $)$ & IMEP $($ bar $)$ & $\lambda$ & $R_{\max }(\mathrm{bar} / \mathrm{deg})$ & COV $(\%)$ \\
\hline 130 & 19.9 & 2.7 & 2.53 & 1.50 & 3.4 \\
100 & 21.5 & 2.6 & 2.26 & 2.59 & 3.9 \\
70 & 21.5 & 2.2 & 2.24 & 1.53 & 3.7 \\
60 & 21.0 & 2.2 & 2.39 & 1.65 & 2.4 \\
50 & 19.4 & 2.0 & 2.43 & 1.52 & 2.9 \\
45 & 17.6 & 1.8 & 2.73 & 1.23 & 3.9 \\
40 & 16.4 & 1.5 & 2.86 & 1.27 & 4.2 \\
35 & 15.3 & 1.4 & 3.13 & 1.28 & 3.4 \\
30 & 13.9 & 2.2 & 3.40 & 1.39 & 2.4 \\
25 & 12.3 & 2.6 & 4.01 & 2.54 & 2.8 \\
20 & 10.9 & 2.8 & 4.36 & 1.77 & 2.7 \\
15 & 12.2 & 2.8 & 4.02 & 4.09 & 2.1 \\
\hline
\end{tabular}

Table S4: Engine experimental test conditions for second set of experiments with PRF 70.

\begin{tabular}{cccccc}
\hline SOI (CAD bTDC) & $\dot{m}_{\text {fuel }}(\mathrm{mg} /$ cycle $)$ & IMEP $(\mathrm{bar})$ & $\lambda$ & $R_{\max }$ (bar/deg) & COV (\%) \\
\hline 130 & 19.90 & 3.5 & 2.39 & 1.73 & 3.8 \\
100 & 21.50 & 3.5 & 2.12 & 1.69 & 2.5 \\
70 & 21.50 & 3.4 & 2.13 & 1.52 & 3.1 \\
60 & 21.00 & 3.5 & 2.31 & 1.49 & 2.1 \\
50 & 19.40 & 3.1 & 2.38 & 1.38 & 3.2 \\
45 & 17.60 & 2.7 & 2.56 & 1.45 & 3.4 \\
40 & 16.40 & 2.9 & 2.77 & 1.52 & 4.2 \\
35 & 15.30 & 2.9 & 2.95 & 1.65 & 3.3 \\
30 & 13.90 & 3.2 & 3.26 & 2.08 & 2.4 \\
25 & 12.30 & 3.4 & 3.97 & 2.27 & 3.9 \\
20 & 10.90 & 3.5 & 4.33 & 1.32 & 2.4 \\
15 & 12.20 & 3.5 & 3.84 & 2.68 & 1.8 \\
\hline
\end{tabular}



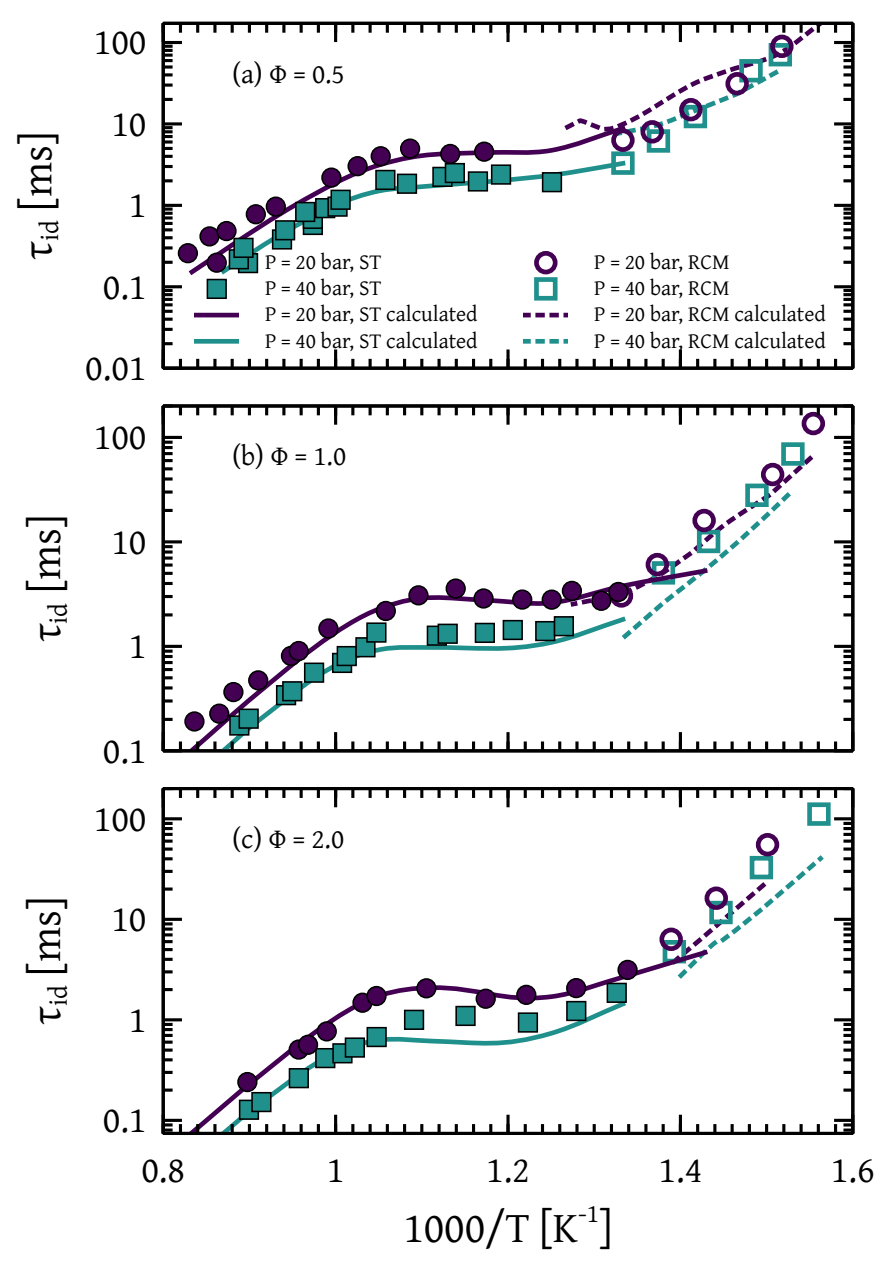

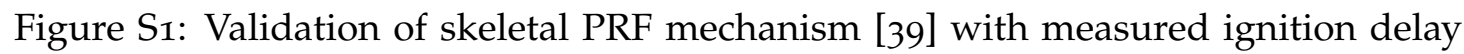
times of LN in [21] at $\phi=($ a) $0.5[$ (b) 1 1.0 (c) 2.0. 


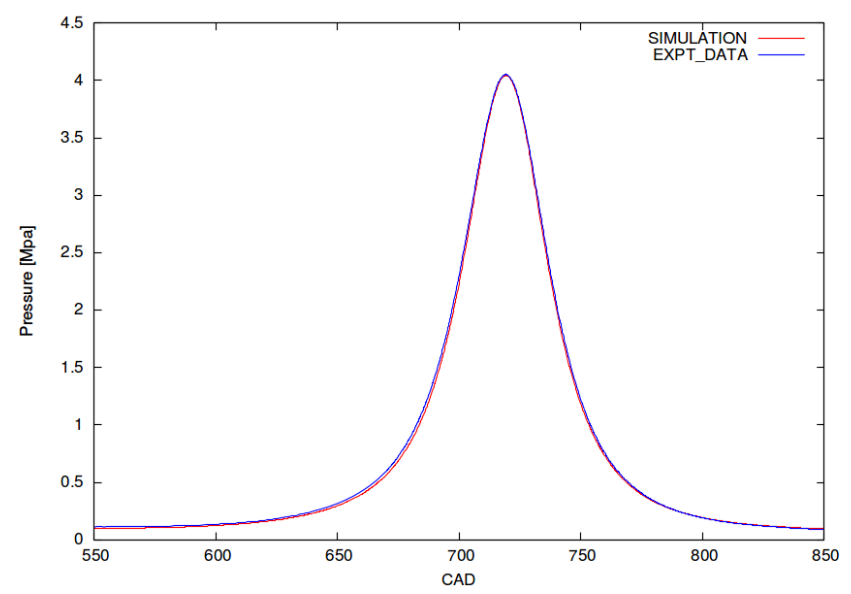

Figure S2: Comparison of simulated and experimental motoring pressure trace (Actual CR - 17.0:1, simulated CR - 16.5:1).

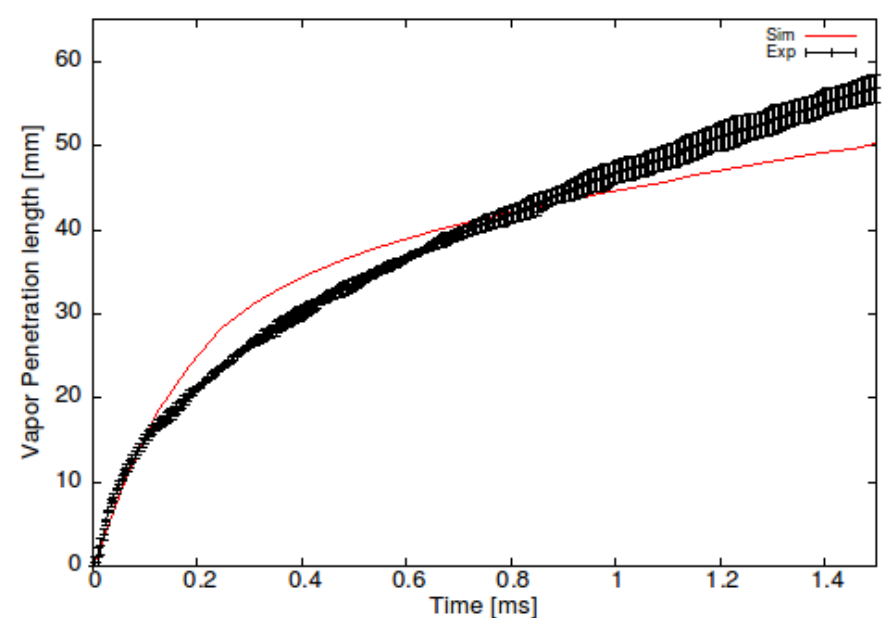

Figure S3: "Spray A" vapor penetration length comparison between experiments and simulations.

A CONSTANT VOLUME CHAMBER NON-REACTING SPRAy SIMULATiONS.

Non-reacting evaporating spray simulations in a constant volume chamber (CVC) can provide more in-depth details about the spray structure and behavior of different fuels in CI environment. Understanding of spray, mixing and turbulence is vital when the engine is operated under PPC condition since the rich "mixture pockets" control the combustion phasing. The spray cone angle, local SMD, liquid and vapor penetration length has a strong influence over the local mixing inside the cylinder. 
Proper predictions of the above said parameters in the absence of gas exchange can provide better insights and help to explain the difference in mixing pattern observed between the four fuels for the same amount of mass at a particular SOI. CVC geometry of $80 \mathrm{~mm}$ of diameter and $90 \mathrm{~mm}$ of height matching the engine's bore and stroke was used in the spray simulations. A base grid size of $4 \mathrm{~mm}$ was used initially with a nozzle embedding reducing the local cell size to $0.25 \mathrm{~mm}$. Adaptive mesh refinement (AMR) was used to refine the cells locally based on the sub-grid criteria of temperature $(5 \mathrm{~K})$ and velocity $(1 \mathrm{~m} / \mathrm{s})$ difference between the neighboring cells. A single-hole injector with nozzle diameter $0.18 \mathrm{~mm}$ was used which is equal to the nozzle diameter of multi-hole ( 7 holes) injector used in engine experiments. The solid spray cone angle was set to $20^{\circ}$ and injection pressure to 300 bar that is representative of one single spray plume of multi-hole injector. KH-RT spray breakup model was used to model the droplet breakup; the constants (Bo, $\mathrm{B}_{1}$ ) were kept the same for all the fuels to avoid the effect of model constants over the prediction results. The evaporation, collision and coalescence model and its constants mentioned in the spray modeling section of engine simulations were used here to maintain consistency between the engine and CVC simulations. Figure Ai shows the geometry developed for the CVC study. The initial temperature and pressure were set to $853 \mathrm{~K}$ and 21 bar, respectively, to represent the engine temperature and pressure at $20^{\circ} \mathrm{CA}$ aTDC. Reynolds Averaged NavierStokes equation was used for time averaging flow with Renormalized group (RNG) k- $\epsilon$ turbulence model to account for the turbulence generated inside the cylinder during the spray injection process. 


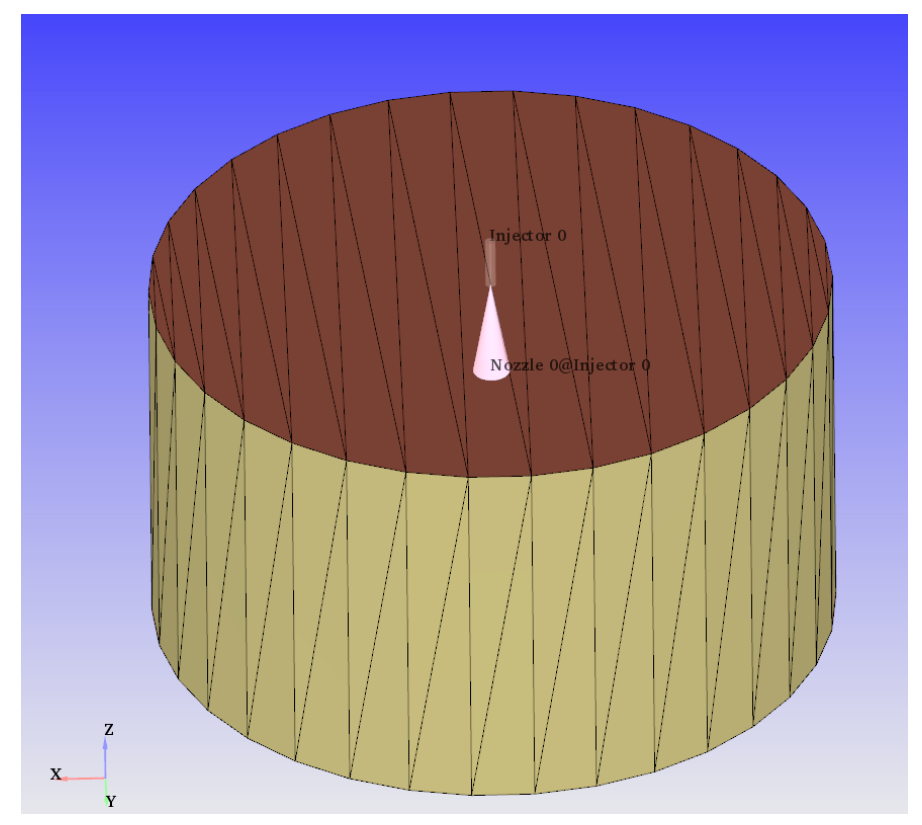

Figure A1: Constant Volume Chamber geometry and mesh generated showing the AMR and embedding during injection. 
B.I In-cylinder mean pressure and heat release rate between fuels at different SOI
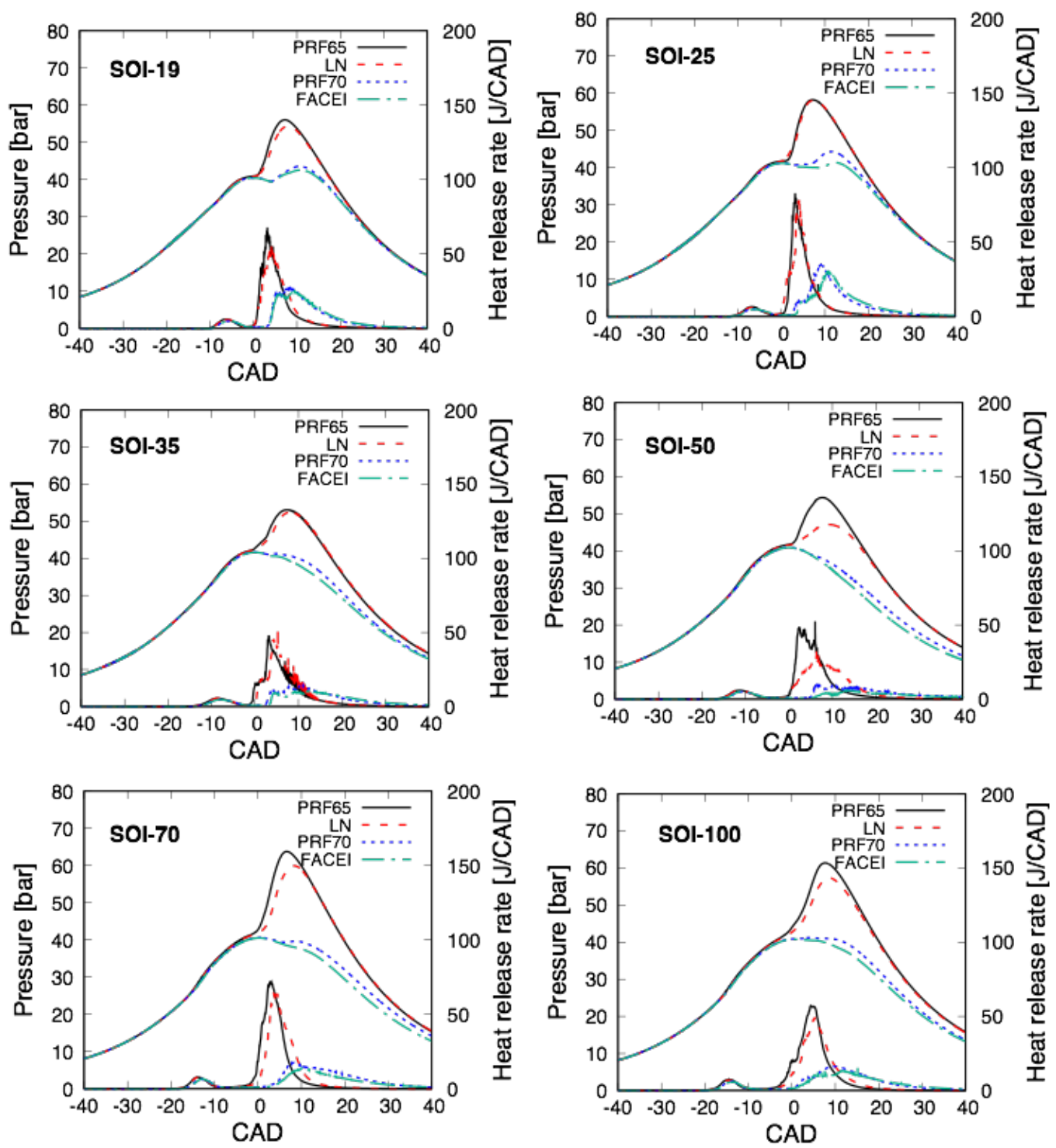

Figure B1: In-cylinder pressure comparison between fuels at different SOI 
B.2 In-cylinder Sauter Mean Diameter (SMD) comparison between fuels at different SOI.
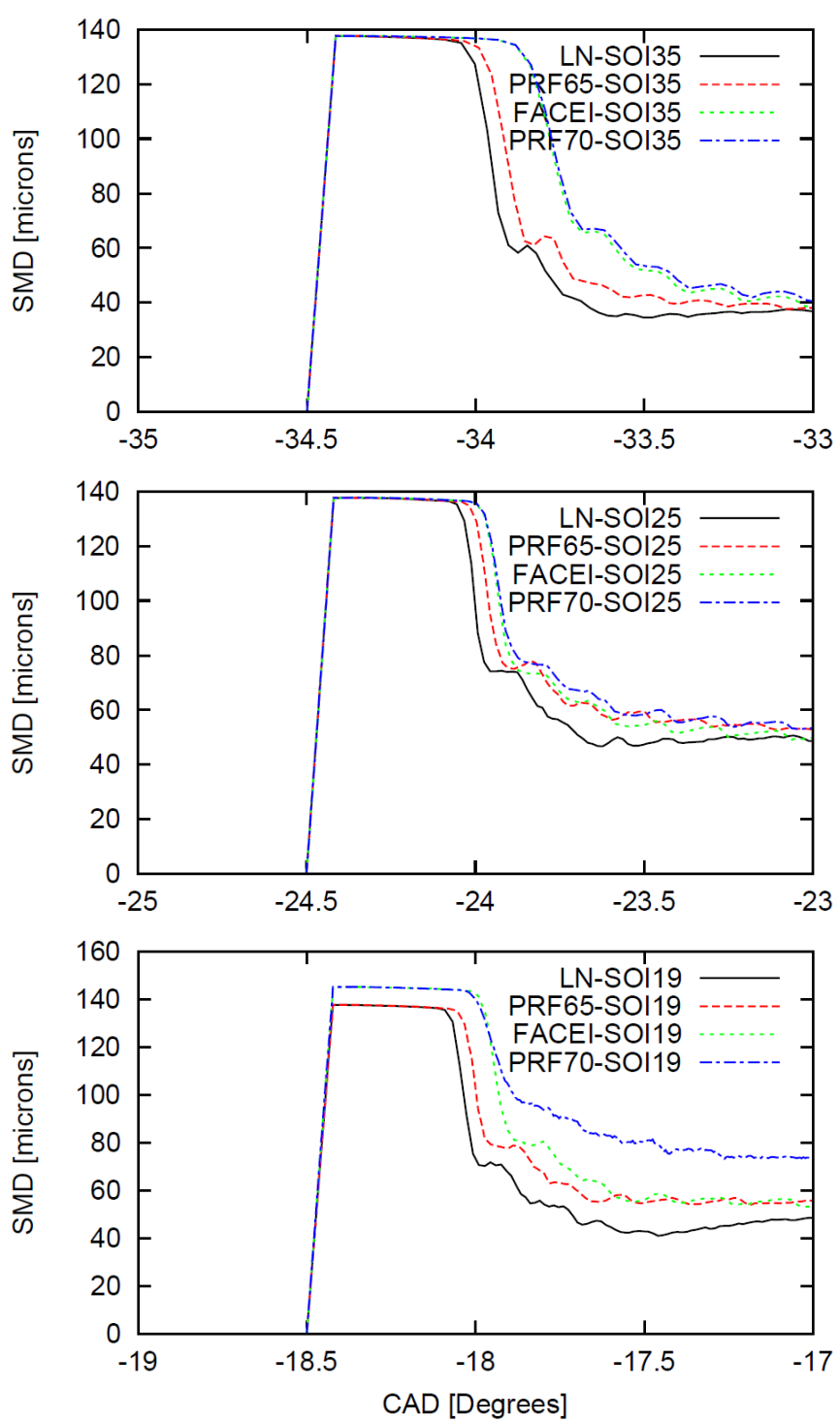

Figure B2: Comparison of SMD for SOI 35, 25, and 19 CAD BTDC. 


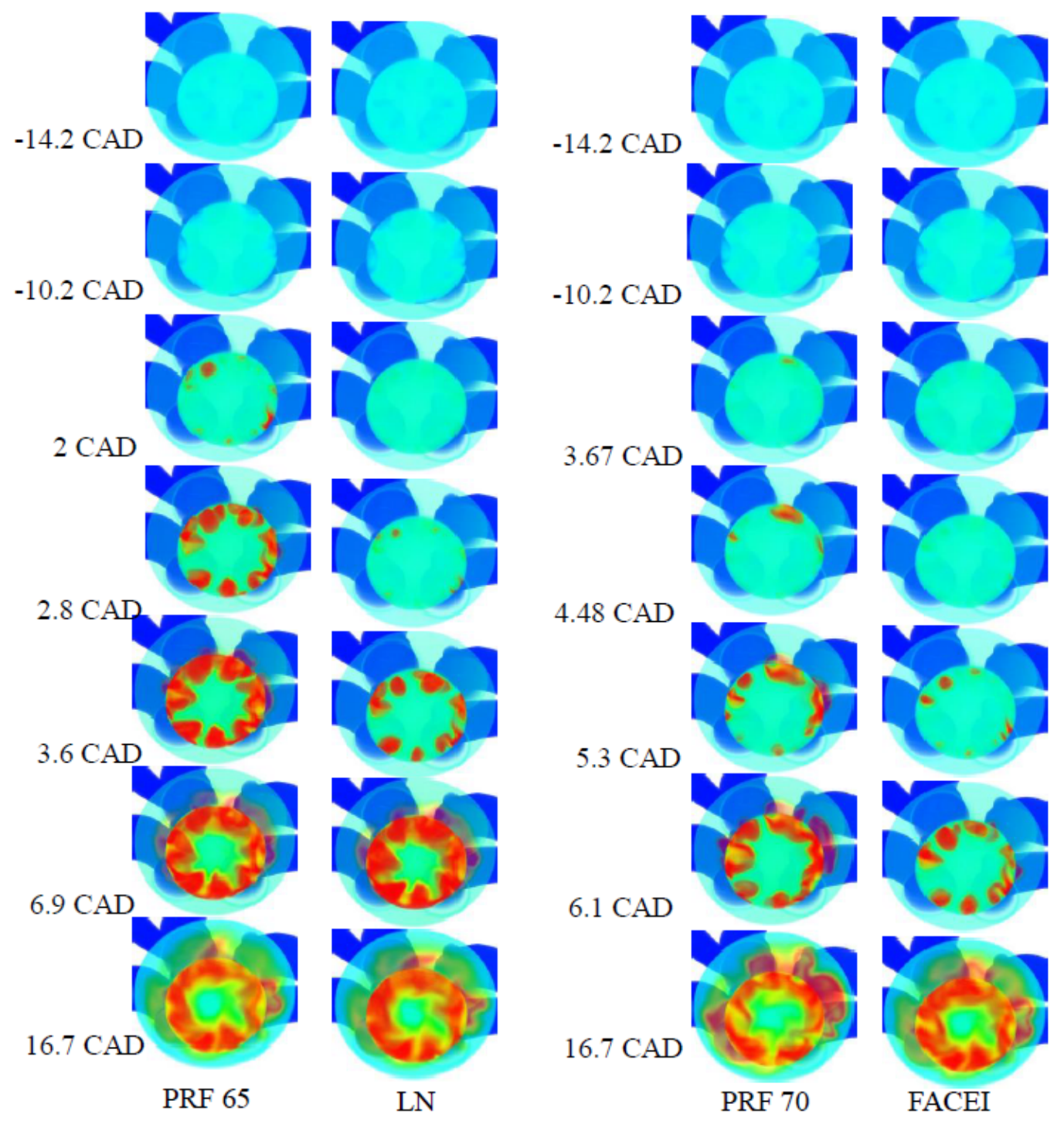

Figure B3: Ignition and combustion progress temperature contour of different fuels for SOI 19 CAD BTDC 